\title{
Crkll Transgene Induces Atypical Mammary Gland Development and Tumorigenesis
}

\author{
Kelly E. Fathers, ${ }^{*}$ Sonia Rodrigues, ${ }^{*}$ \\ Dongmei Zuo, ${ }^{\dagger \ddagger}$ Indrani Vasudeva Murthy, ${ }^{\S}$ \\ Michael Hallett, ${ }^{\S}$ Robert Cardiff, ${ }^{\text {"ा }}$ \\ and Morag Park ${ }^{\star \dagger \ddagger}$ \\ From the Departments of Biochemistry, ${ }^{*}$ Medicine, ${ }^{\dagger}$ and \\ Oncology, ${ }^{\ddagger}$ and the McGill Center for Bioinformatics, ${ }^{\S}$ Rosalind \\ and Morris Goodman Cancer Centre, McGill University, \\ Montréal, Canada; and the Department of Pathology, " School of \\ Medicine, University of California Davis, Davis, California
}

The v-Crk protein was originally isolated as the oncogene fusion product of the CT10 chicken retrovirus. Cellular homologues of v-Crk include Crk, which encodes two alternatively spliced proteins (CrkI and CrkII), and CrkL. Though CrkI/II proteins are elevated in several types of cancer, including breast, the question of whether these Crk adaptor proteins can promote breast cancer has not been addressed. We created a transgenic mouse model that allows the expression of CrkII through the hormonally responsive mouse mammary tumor virus promoter. During puberty, transgenic mice were found to have delayed ductal outgrowth, characterized by increased collagen surrounding the terminal end buds. In post-pubertal mice, precocious ductal branching was observed and associated with increased proliferation. Focal mammary tumors appeared in a subset of animals, with a latency of approximately 15 months. Mouse mammary tumor virus/CrkII tumors showed high levels of Crk protein as well as various cytokeratin markers characteristic of their respective tumor pathologies. This study demonstrates that the precise expression of CrkII is critical for integrating signals for ductal outgrowth and branching morphogenesis during mammary gland development. Furthermore, this study provides evidence for a potential role of CrkII in integrating signals for breast cancer progression in vivo, which has important implications for elevated CrkII observed in human cancer. (Am J Pathol 2010, 176:446-460; DOI: 10.2353/ajpath.2010.090383)

Crk was originally isolated as the oncogene fusion product of the CT10 chicken retrovirus (v-Crk) in chicken fibrosarcomas. ${ }^{1}$ Cellular homologues of $\mathrm{v}$-Crk include $\mathrm{C}$ Crk, which encodes two proteins (c-Crkl and c-Crkll) through alternative splicing, and the related protein $\mathrm{c}$ CrkL. Crk proteins consist of Src homology $2(\mathrm{SH} 2)$ and Src homology 3 (SH3) domains. ${ }^{2}$ Crkl contains one $\mathrm{SH} 2$ domain and one $\mathrm{SH} 3$ domain, whereas Crkll also contains a linker region (containing a Y221 negative regulatory site) and a second $\mathrm{SH} 3$ domain at the C-terminus. ${ }^{2}$ CrkL is similar to Crkll with one $\mathrm{SH} 2$ domain and $2 \mathrm{SH} 3$ domains, and shares $60 \%$ homology with Crkll. ${ }^{3}$ Crkl, Crkll, and CrkL are all expressed in several tissue types, though Crkl is generally expressed at lower levels than CrkIl, and CrkL is highest in hematopoietic tissues. ${ }^{3,4}$

Crk adaptor proteins have no enzymatic activity but rather play an important role during cellular signaling by mediating the formation of protein-protein complexes. ${ }^{2}$ In response to extracellular stimuli, Crk has been implicated in cellular processes including cell migration, invasion, adhesion, proliferation, apoptosis, or phagocytosis, depending on the signal transduction pathway activated and the effector proteins involved. ${ }^{2}$ For instance, in response to hepatocyte growth factor, Crk proteins are required for dispersal of organized epithelial colonies, the formation of lamellipodia, and the breakdown of adherens junctions, all of which are events critical for tumor cell dispersal, invasion and, hence, cancer progression. ${ }^{5}$ Overexpression of Crk promotes an invasive phenotype regardless of upstream signaling, identifying Crk as a key modulator of upstream signals for cell invasion. ${ }^{6}$ Moreover, Crk proteins are elevated in multiple types of human

Supported by a grant to M.P. from the Terry Fox Foundation New Frontiers Program Project. K.E.F. is a recipient of US Army Department of Defense scholarship. M.P. is the Diane and Sal Guerrara Chair in Cancer Genetics at McGill University.

Accepted for publication September 18, 2009

Supplemental material for this article can be found on http://ajp. amjpathol.org.

The current address for S.R. is Department of Anatomy and Cell Biology, McGill University, Montreal Neurological Institute, Montreal QC, H3A 2B4, Canada.

Address reprint requests to Morag Park, Ph.D., Rosalind and Morris Goodman Cancer Centre, 1160 Pine Avenue West, Room 514, Montreal, QC H3A 1A3. E-mail: morag.park@mcgill.ca. 
cancer, including lung carcinoma, glioblastoma, and breast cancer. ${ }^{7-10}$

All three Crk proteins (Crkl, Crkll, CrkL) have been shown to be involved in transformation in vitro, albeit to varying degrees. Crkl, which most closely resembles v-Crk, has demonstrated the highest transforming potential. Fibroblast cells expressing Crkl proliferate in soft agar and form tumors in nude mice. ${ }^{11}$ Although Crkll was thought to have no transforming activity, ${ }^{11}$ a more recent study has shown that overexpression of Crkll in NIH3T3 fibroblasts and various mouse embryo fibroblasts can induce growth in soft agar, suggesting that Crkll can play a role in anchorage-independent growth, one component of cell transformation. ${ }^{12}$ Overexpression of CrkL also leads to anchorage-independent growth in fibroblasts. ${ }^{13}$ Significantly, a mouse model overexpressing CrkL through its endogenous promoter at a high copy number was associated with an increased incidence of leukemogenesis in Bcr-Abl transgenic animals. ${ }^{13,14}$ Although evidence supports that all three Crk proteins are capable of transforming cells in culture, few studies have addressed their role in vivo and no studies have specifically examined Crk in epithelial derived cancers.

Most in vitro studies on Crkll have focused on fibroblasts, however, Crkll is well-expressed in the epithelium of many tissues. ${ }^{4}$ Furthermore, although Crkl/II has been shown to be overexpressed in breast cancer, no information is known about whether $\mathrm{Crkl} / \mathrm{ll}$ adaptor proteins can contribute to the formation of the disease. Thus, to examine the importance of Crkll in both tumor progression and mammary gland development, we derived transgenic mice expressing Crkll in the mammary epithelium, under the transcriptional control of the mouse mammary tumor virus promoter (MMTV).

\section{Materials and Methods}

\section{Plasmid Construction and Generation of Transgenic Mice}

For transgenic mice, pSport6-Crkll (Open Biosystems, NM_016823) was cloned into pDONR201 using the Gateway Vector Conversion System (Invitrogen, Burlington, Canada) then subsequently cloned into p206 vector containing attR cloning sites, the MMTV promoter, and the SV40 polyadenylation sequence. To generate transgenic mice, a purified 6.3 Kb MMTV-Crkll fragment was microinjected into pronuclei of FVB and the generation of chimeric mice was performed at the McGill Transgenic Facility, McGill University. Mice were housed in the Royal Victoria Hospital (Montreal, Canada) transgenic mouse facility and all experiments were performed in accordance with McGill University Animal Ethics Committee guidelines.

\section{Genotyping of Transgenic Mice}

Transgenic mice were identified by PCR using DNA extracted from tail tips. PCR reactions were performed using two SV40 specific primers: forward 5'-GGAACCT-
TACTTCTGTGGTGT-3' and reverse 5'-GCATCCCACCACTGCTCCCATTC-3' which gave rise to a product of $350 \mathrm{bp}$. To examine expression levels of the transgene, total RNA was extracted, isolated, and purified from mammary glands using Trizol reagent (Invitrogen) according to the manufacturer's protocol. Reverse transcription (RT) reactions were performed using oligodT for priming (Invitrogen) and Superscriptll reverse transcriptase (Invitrogen). Real-time PCR was performed using the Rotor Gene Real-time thermocycler (Corbett Research, Sydney, Australia). The housekeeping gene ALAS1 was used as a control (5'-CCACTGGAAGAGCTGTGTGA-3' and $3^{\prime}$-TGGCAATGTATCCTCCAACA-5'). The values for each sample obtained from a standard curve were used to determine the expression levels of the transgene by dividing the SV40 value over the housekeeping gene.

\section{Wholemount Analysis of Mammary Glands}

Right inguinal mammary glands (\#4) were processed according to previously published methods. ${ }^{15}$ Wholemount images were captured using AxioVision software (Carl Zeiss, Toronto, Canada) and a Zeiss microscope (Carl Zeiss).

\section{Quantification of Ductal Development from Wholemounts}

To quantitate ductal outgrowth, images of wholemounts from mice at 10 weeks of age were captured using a microscope and AxioVision software (Carl Zeiss) at a magnification of $\times 0.6$. Using Scion Image-NIH equivalent software for Microsoft Windows (Scion Company, Frederick, MD), the distance from the lymph node to the terminal end bud and the lymph node to the edge of the fat pad was calculated. This calculates the percentage of mammary fat pad by comparing the distance traveled by the leading end buds to the total length of the fat pad.

Increased stroma (eg, fibroblasts, immune cells, extracellular matrix) surrounding terminal end buds was imaged on wholemounts at $\times 20$ and was observed as a "halo" that surrounded the epithelial ducts and end buds. The percentage of terminal end buds with enhanced stroma (or halo-like structures) was quantified and represented as a percentage relative to the total number of terminal end buds present within the mammary glands.

To quantitate the average diameter of end buds, three measurements were taken from the widest portion of each terminal end bud and the average diameter was calculated for the MMTV/CrkIl and the FVB mice using Image J software (National Institute of Health, MD), which were then expressed as a percentage. For mice at 10 weeks of age, six control mice and six MMTV/Crkll mice were examined.

Quantification of Ki-67 staining on paraffin-embedded sections derived from 20-week-old MMTV/CrkII and FVB mice was performed using Image Scope software (Quorum Technologies, Guelph, Canada). Quantification was performed using a nuclear algorithm that distinguished between hematoxylin-stained (blue) cells 
and Ki-67-positive (brown) cells. Using annotation tools, the lymph node was excluded from analysis. Mammary glands from five MMTV/Crkll mice and four FVB control mice were used for analysis.

\section{Histology}

Left inguinal mammary glands (\#4) were fixed in 10\% neutral buffered formalin (Surgipath, Richmond, IL) overnight, transferred to $70 \%$ ethanol, and paraffin-embedded. Sections were stained with H\&E, or Masson's Trichrome staining. All images were captured using the Aperio Slide Scanner and Image Scope software (Quorum Technologies).

\section{Immunohistochemistry}

All paraffin sections $(4 \mu \mathrm{m})$ were deparaffinized and rehydrated in a series of incubations in xylene and ethanols, and washed in $1 \times$ PBS. All antibodies were diluted in PBS containing $2 \%$ bovine serum albumen. Antigen retrieval was performed using $10 \mathrm{mmol} / \mathrm{L}$ sodium citrate $\mathrm{pH}$ 6.0. Sections were then washed in water followed by PBS. Endogenous peroxidases were removed by washing in 3\% hydrogen peroxide (Fisher Scientific, Canada). Sections blocked in $2 \%$ bovine serum albumen were then incubated with primary antibody overnight at room temperature, then with secondary antibody for 30 minutes at room temperature. Sections were washed and, if biotinylated, subjected to an $\mathrm{ABC}$ reagent for 30 minutes (Vector, Burlingame, CA). After washing, sections underwent a diaminobenzidine substrate reaction (DAKO Cytomation, Glostrup, Denmark), were counterstained with hematoxylin and mounted using Acytrol. Primary antibodies included: Ki-67 (1:1500), Crk (1:200), cytokeratin (CK)8 (1:1200), CK6 (1:800), CK14 (1:1000), smooth muscle actin (SMA; 1:500), proliferating cell nuclear antigen (1: 1500), vimentin (1:1500), netrin-4 (1:100), and laminin (1:100). Staining for proliferating cell nuclear antigen was performed using the Mouse on Mouse staining kit (Chemicon, Temecula, CA). The secondary antibody for Crk and SMA was anti-mouse horseradish peroxidase (1:500), whereas Ki-67, laminin, CK14, and CK6 used the anti-rabbit Vectastain biotinylated antibody (Vector). CK8 staining required the biotinylated anti-guinea pig whereas vimentin and netrin-4 required the biotinylated anti-goat secondary antibody (Vector). The F4/80 staining required the biotinylated anti-rat secondary antibody (Vector). The proliferating cell nuclear antigen antibody was purchased from DAKO Cytomation, CK8/18 from Fitzgerald Industries International (Concord, MA), and CK14 and CK6 were from Covance (Berkley, CA). The rabbit polyclonal antibody recognizing $\mathrm{Ki}-67$ was purchased from Abcam (Cambridge, MA). Monoclonal antibodies for Crk and vimentin were purchased from BD Transduction Laboratories (Lexington, KY), SMA and laminin from Sigma Aldrich (Oakville, Canada), Ki-67, F4/80, and netrin-4 from Cedarlane Laboratories (Hornby, Canada). For terminal deoxynucleotidyl transferase dUTP nick-end labeling, the TUNEL Apoptag Plus
Peroxidase In Situ Detection system was used according to the manufacturer protocol (Chemicon). All images were captured using the Aperio Slide Scanner and Image Scope software. Immunofluorescence of mammary wholemounts was performed according to standard procedures. ${ }^{16}$

\section{Protein Analysis and Antibodies}

Mouse mammary glands were lysed and whole cell lysates were resolved by SDS-polyacrylamide gel electrophoresis in $12 \%$ gels as previously described. ${ }^{8}$ The connective tissue growth factor (CTGF) antibody was generously provided by Dr. Peter Siegel's laboratory. Densitometry was performed using Image J Software.

\section{Analysis of Tumor Formation}

Mammary glands with visible tumor formation were resected. Tumor pieces were snap frozen in liquid nitrogen or fixed in $10 \%$ neutral buffered formalin.

\section{Microarray Analysis}

T47D and T47D-Crkll cells were cultured as previously described and either harvested for protein or RNA. ${ }^{5}$ RNA was isolated using Trizol and then quantified and amplified according to previous methods. ${ }^{17}$ The RNA was subsequently labeled with Cy5 and hybridized against Cy3 labeled Universal Human Reference RNA (Stratagene) on $1 \times 44 \mathrm{~K}$ Human Oligo microarray chips purchased from Agilent Technologies (Palo Alto, CA). Microarrays were washed and scanned using Agilent's dual-laser microarray scanner (Model G2505B) according to the manufacturer's instructions. Cy3/Cy5 signals were quantified using Agilent Feature Extraction software (Palo Alto, CA). Microarray normalization was performed as previously described. ${ }^{18}$ Differential expression was evaluated using Linear Models for Microarray Data (LIMMA) and Benjamin-Hochberg and a multiple testing correction was applied. A hypergeometric test was used to identify Gene Ontology (GO) and Kyoto Encyclopedia of Genes and Genomes (KEGG) categories overrepresented in the set of differentially expressed genes.

\section{$R T-P C R$}

RNA used for the microarrays (before amplification) was reverse-transcribed, according to the manufacturer's direction (Roche, Canada). RT-PCR analysis was performed using the Qiagen SYBR Green kit and a Roche lightcycler (Roche, Canada). A standard curve was created by combining equal amounts of each sample and performing serial dilutions. Primers were: Calponin1, 5'-CCAGCCCCTGTAGAACTCAA-3' Calponin1, 3'-ACAGCTGGAATAGCGTTGCT-5'; Netrin 4, 5'CAGCAGCACTGCCACTACAT-3' Netrin 4, 3'-CATCATGGCTGTCATCTTGG-5'; CTGF, 5'-GGAAAAGATTCCCACCCAAT-3', CTGF, 3'-TGCTCCTAAAGCCACACCTT-5'; progesterone receptor, 5'-ACATG- 
A

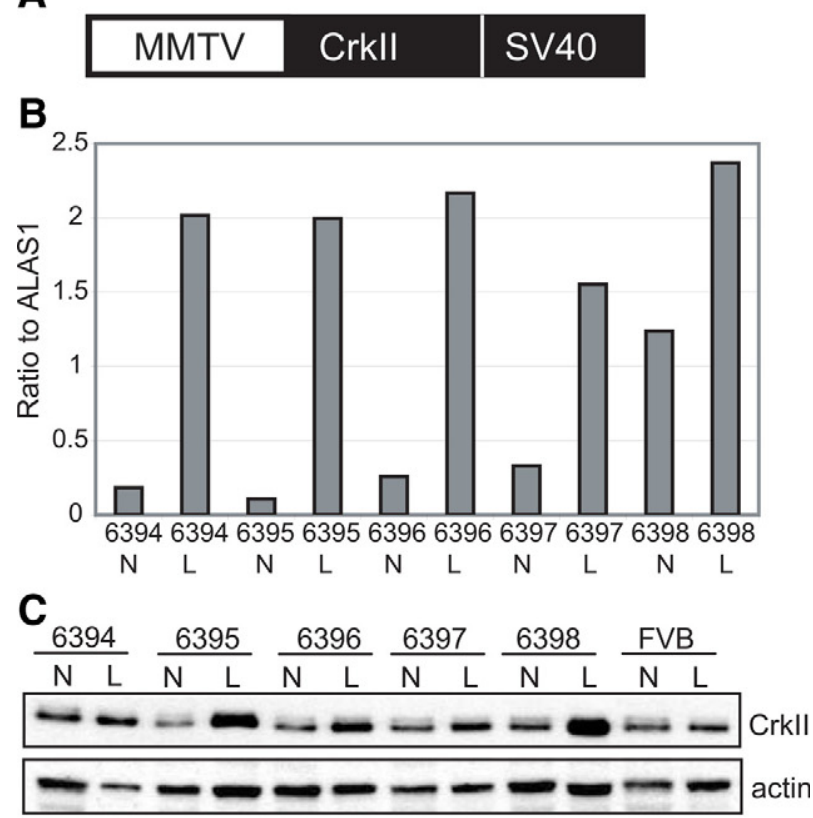

D
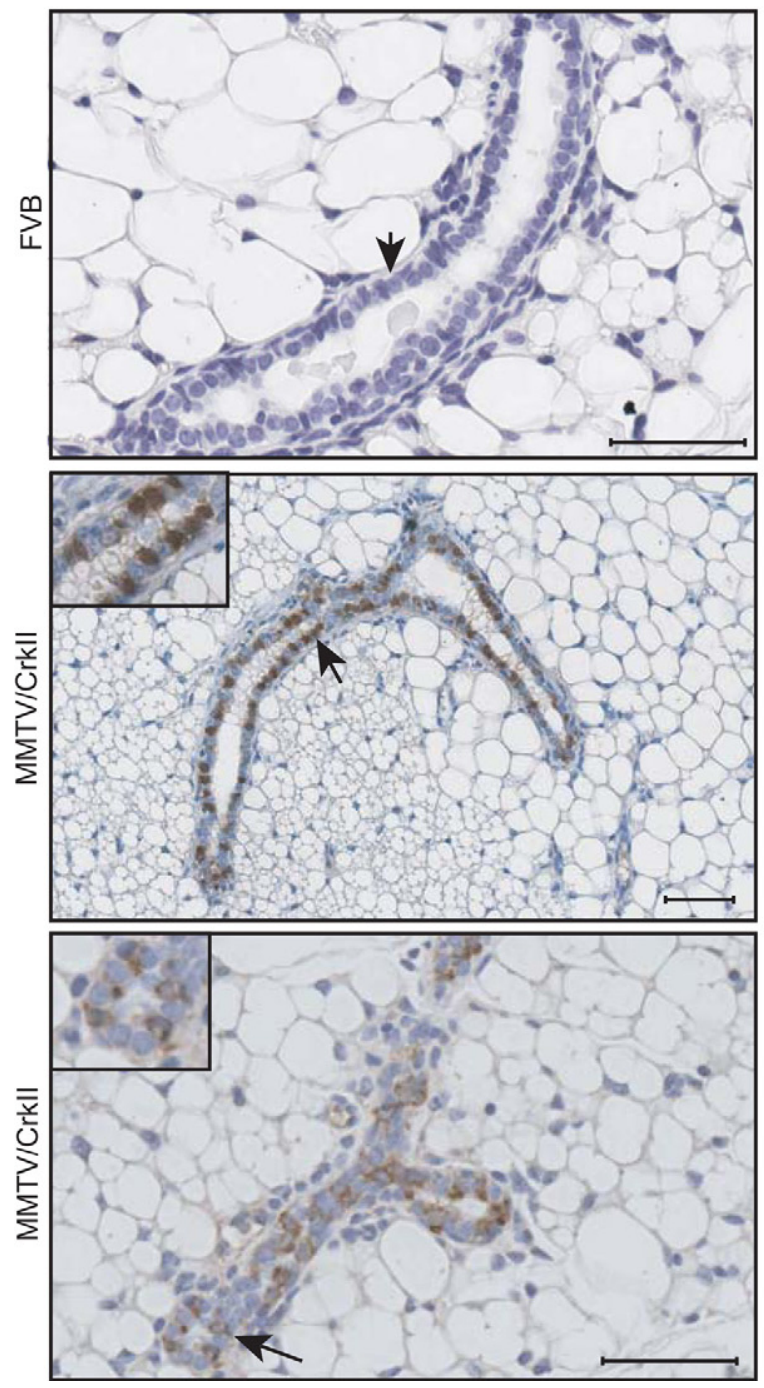

GTAGCTGTGGGAAGG-3', progesterone receptor, 3'-GCTAAGCCAGCAAGAAATGG-5'; and collagen12alpha1, 5'-CAGGTTCCGGCTAACACATT-3', collagen12alpha1, 3'-GTCTCCACCCTCCTTTGTGA-5'.

\section{Statistical Analysis}

Results were expressed as the mean \pm SE. Statistical analysis of data were performed using a Student's $t$-test.

\section{Results \\ Overexpression of Crkll in the Mammary Epithelium Leads to Defects in Ductal Outgrowth}

To determine the effects of overexpression of Crkll on mammary gland physiology and tumorigenesis, MMTV/ Crkll transgenic mice were generated (Figure 1A). Five positive founder lines were further characterized for transgene expression. Mammary glands from both nulliparous and lactating female mice were examined for expression levels of the transgene by quantitative RTPCR and Western blot analysis (Figure 1, B and C). The MMTV promoter induces high expression during pregnancy and lactation, although transgene expression is detected in the nulliparous mammary gland during puberty. ${ }^{19}$ Expression of the Crkll transgene using primers specific for the transgene SV40 polyA signal indicated that the transgene was expressed in each founder line in both nulliparous and lactating mice (Figure 1B). Moreover, as expected, Crkll protein was higher in lactating transgenic mice than their wild-type counterparts (Figure 1C). Immunohistochemistry on sections from paraffin-embedded mammary epithelium revealed intense but heterogeneous Crk expression in both the nucleus and the cytoplasm of luminal epithelium in transgenic mice when compared with control FVB mice (Figure 1D). MMTV/CrkII lines (6396 and 6398) with the highest levels of mRNA expression specific for the transgene (Figure 1B) were used for further study.

To determine whether overexpression of Crkll in the mammary epithelium could perturb normal mammary gland development, wholemounts of nulliparous mammary glands were examined during puberty. At this particular stage of development, terminal end buds form, which are large, bulbous structures of active proliferation and differentiation. ${ }^{20}$ Dichotomous branching of the terminal end buds, along with secondary side branching

Figure 1. Expression of the CrkII transgene in the mammary epithelium. A The design of the MMTV/CrkII transgene. B: Expression of transgene using primers specific for the SV40 region indicates the CrkII transgene is well expressed in each transgenic line. Housekeeping gene examined was ALAS1. Quantitative real-time PCR data illustrating the varying expression levels of the transgene in nulliparous $(\mathrm{N})$ and lactating $(\mathrm{L})$ female mice $(n=2$ per $\mathrm{N}$ and L) among the various transgenic lines (6394-6398). C: Expression of CrkII protein levels in transgenic and FVB mice in both nulliparous (N) and lactating (L) animals. D: Immunohistochemistry of CrkII (middle lower panels) in nulliparous transgenic mouse mammary epithelium compared with a normal representative FVB littermate (upper panel). Images taken at $\times 20$. Scale bar $=50 \mu \mathrm{m}$. Arrows represent the luminal epithelium. 
A

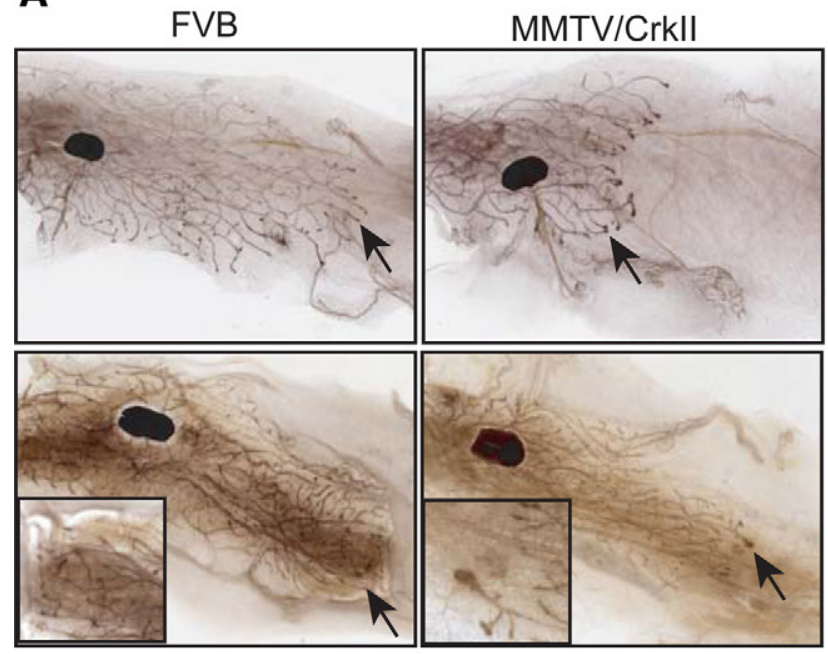

C
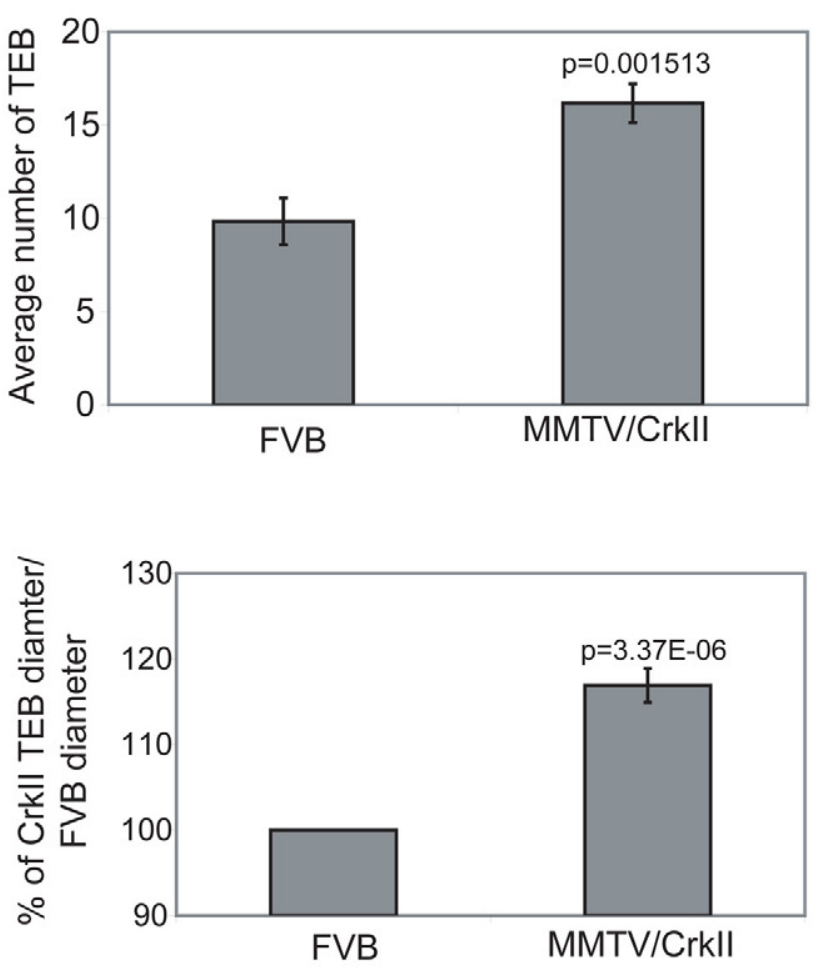

B

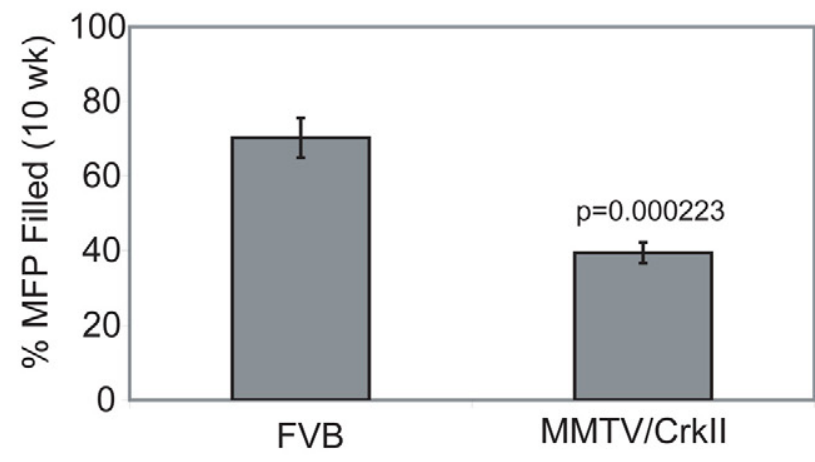

D
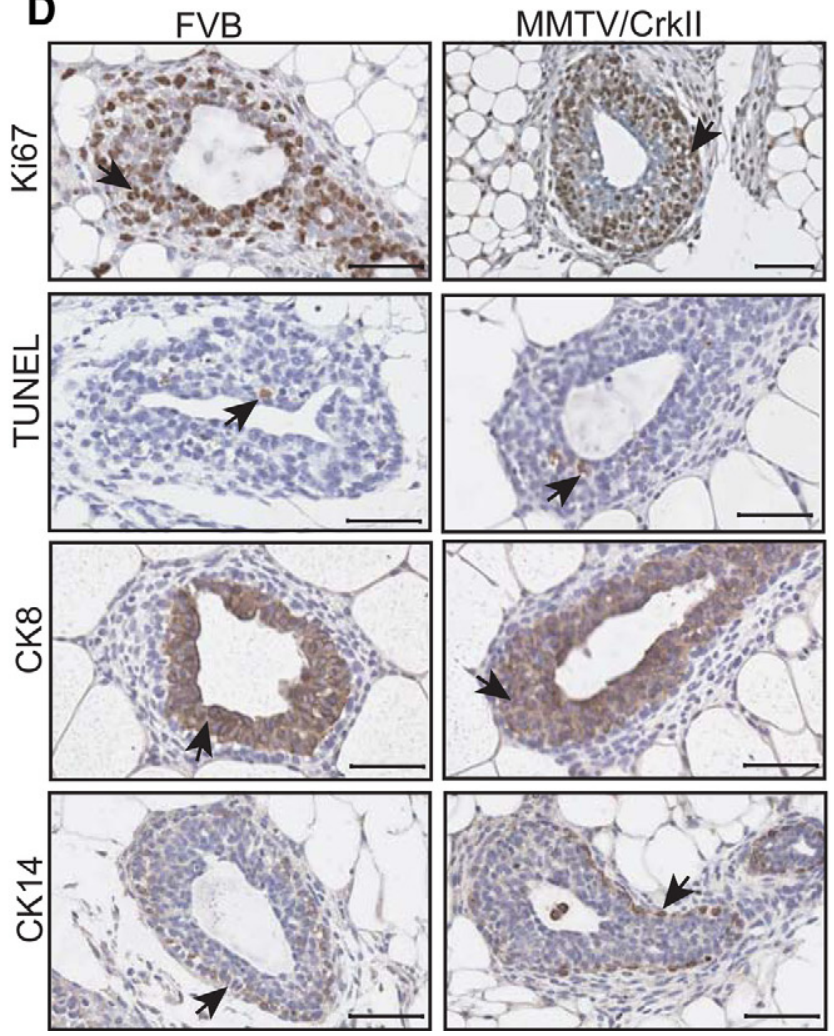

Figure 2. Delayed ductal outgrowth in MMTV/CrkII transgenic mice compared with normal FVB littermates. A: Delayed ductal outgrowth in transgenic mice was detected at 5 weeks (data not shown), 10 weeks (upper right panel), and 12 weeks (lower right panel) relative to FVB mice at the same age (upper and lower left panels). Images taken at $\times 0.6$. Arrows represent the terminal end bud structures. B: The percentage of fat pad filled by epithelial ducts was calculated using Scion Image for six FVB mice and six CrkII mice at 10 weeks of age and the average percentage was determined \pm SE (ii), $P<0.05$. The distance from the lymph node to the terminal end bud over the distance of the lymph node to the end of the fat pad was determined and expressed as a percentage. C: The average number of terminal end bud structures among FVB $(n=6)$ and MMTV/CrkII mice $(n=6)$ and the percentage of increased diameter size of these structures within CrkII mice relative to FVB control mice \pm SE, $P<0.05$. D: Paraffin-embedded sections of 10 -week-old mammary glands from six FVB and six MMTV/CrkII mice were stained for Ki-67 and further comparison of FVB terminal end buds to those from MMTV/CrkII transgenic mice were examined using the ApopTag Plus Peroxidase In Situ Detection system. Staining patterns of CK8 and CK14 were also visualized in FVB versus CrkII transgenic mice. All images taken at $\times 20$; scale bar $=50$ $\mu \mathrm{m}$. Arrows represent positive staining.

results in the expansion of the ductal tree, until the mammary fat pad is filled. At the end of puberty, when the ductal tree has expanded to reach the edges of the fat pad, the terminal end bud structures then regress. ${ }^{20}$ Mammary glands from nulliparous mice at various stages of puberty (5 to 12 weeks) displayed delayed ductal outgrowth compared with their wild-type FVB littermates (Figure 2A). The suppression of ductal outgrowth was most significant between 7 to 10 weeks of age. Thus, the inhibitory effect of Crkll on mammary ductal outgrowth was quantified by determining the percentage of fatty stroma filled by the ducts and end buds (Figure 2B). This 
was calculated by comparing the distance traveled by the leading end buds to the total length of the mammary fat pad. Inhibition of ductal outgrowth was most pronounced at 10 weeks of age, with an inhibition of $31 \%$ (Figure 2B). However, in MMTV/Crkll mice at 12 weeks of

\section{A}

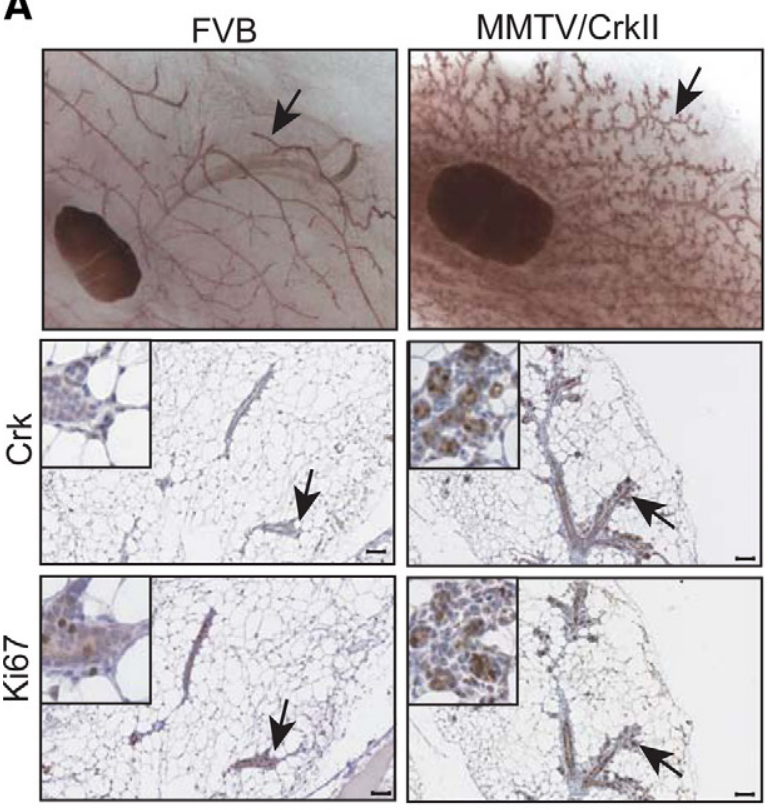

B

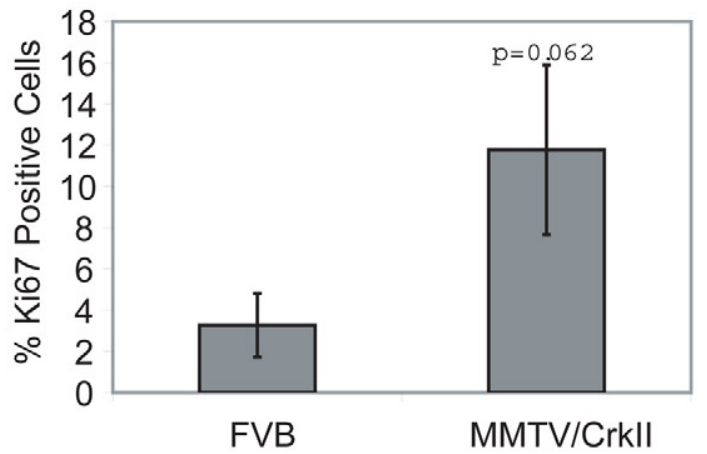

C
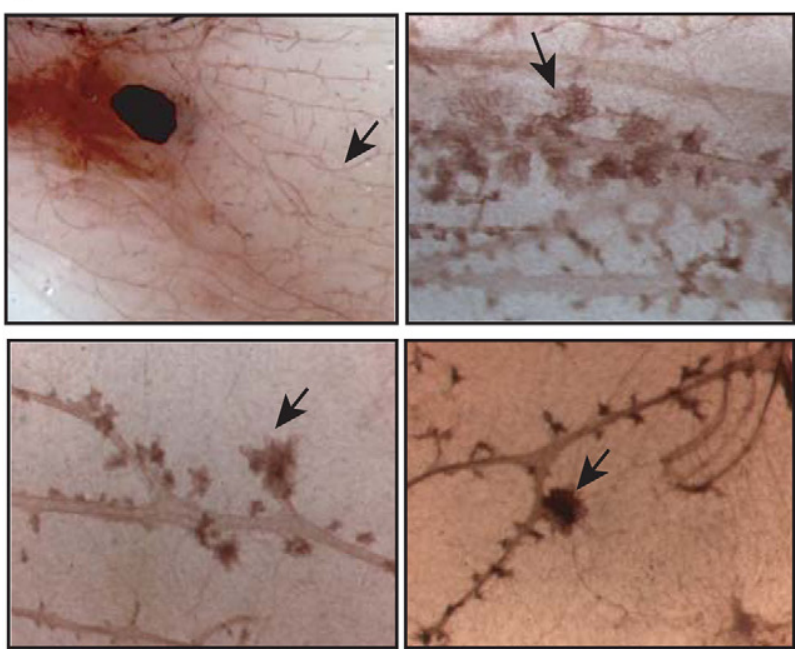

age, terminal end buds were still persistent and disorganized, and had not yet reached the edges of the fat pad, whereas in their wild-type littermates, these buds were regressed and the fat pads were filled with branching ducts (Figure 2A). In addition, the average number of terminal end buds in a gland were increased in the MMTV/Crkll mice $(16, n=6)$ relative to control mice (9, $n=6)$ at 10 weeks of age and the average diameter of these structures was 18\% larger (Figure 2C).

As previously mentioned, cellular proliferation and differentiation are active processes within terminal end buds. ${ }^{21}$ Proliferative epithelial cells drive the expansion of the mammary tree, and cap cells and body cells differentiate into basal myoepithelial cells, and luminal cells respectively. ${ }^{20,21}$ Active apoptosis also occurs within the terminal end buds to create the lumen of the ducts. ${ }^{20}$ However, suppression of ductal outgrowth did not coincide with significant changes in cell proliferation, apoptosis, or differentiation (through staining of Ki-67, terminal deoxynucleotidyl transferase dUTP nick-end labeling, CK8, and CK14 respectively) between control and MMTV/CrkII mice at 10 weeks of age (Figure 2D). Indeed, quantification of Ki-67 positive cells did not reveal a significant increase in the percentage of proliferating cells within the MMTV/Crkll transgenic mice (49.6\%) relative to the wild-type mice (39.2\%) (See Supplemental Figure S1 at http://ajp.amjpathol.org). Additional staining on FVB and MMTV/Crkll wholemounts at 5 weeks of age were analyzed for Ki-67 (proliferation), CK8 (luminal epithelial marker), and SMA (myoepithelial and fibroblast marker) through immunofluorescence, and no obvious differences were seen (See Supplemental Figure S1 at http://ajp.amjpathol.org).

In addition to growth regulation and cellular differentiation, ductal outgrowth depends on the integrity of the end bud structure since perturbations that alter cellular adhesion or cell-cell contact can inhibit ductal extension. ${ }^{21}$ Crkll has been shown to play a role in cellular adhesion and cell-cell contact, however, by indirect immunofluorescence, no alterations were visualized in Ecadherin and ZO-1 localization, which are markers of adherens and tight junctions, respectively (See Supplemental Figure S2 at http://ajp.amjpathol.org). Therefore, multiple lines of transgenic mice with elevated levels of Crkll in the mammary epithelium display a delay in mammary development during puberty by suppressing the

Figure 3. Enhanced branching of MMTV/CrkII mice at 20 weeks of age. A: In comparison with a wild-type FVB littermate (upper left panel, $\times 2$ ), MMTV/CrkII transgenic mice show enhanced branching (see black arrows) (upper right panel, $\times 2$ ). Branching ducts show high levels of CrkII protein relative to normal FVB littermates (see black arrows, middle panels) Staining for Ki-67 reveals active proliferation of the epithelial cells in MMTV/ CrkII mammary ducts, whereas little proliferation is visualized in FVB mice (see black arrows, lower panels). All immunohistochemistry images taken at $\times 10$. Scale bar $=50 \mu \mathrm{m}$. B: Quantification of Ki-67 positive cells in 20-week-old FVB versus MMTV/CrkII transgenic mice, as determined using ImageScope analysis software. C: Aging nulliparous CrkII mice show a wide variety of phenotypes. Aging nulliparous mice sacrificed between 12 to 15 months display atypical epithelial architecture, such as lobuloaveoli (upper right panel, $\times 6.6$ ), spiculated ends (lower left panel, $\times 6.6$ ), and hyperplastic-like lesion (lower right panel, $\times 6.6$ ) relative to an FVB mouse of the same age (upper left panel, $\times 0.6$ ). Black arrows represent highlight the differential architecture. 
outgrowth of epithelial ducts without any obvious effects on proliferation, apoptosis, cell-cell contact, adhesion, or cell differentiation.

\section{Crkll Transgene Leads to Enhanced Mammary Gland Branching Characterized by Increased Proliferation}

Ductal outgrowth within the MMTV/Crkll transgenic mice is complete by 14 weeks of age. Once fully developed, there is a discrete Crk-dependent phenotype in the mammary glands of post-pubertal mice, evidenced by increased ductal branching and enhanced proliferation (Figure 3A). This is accompanied by elevated Crk staining in the branching epithelium (Figure 3A). Quantification of Ki-67-positive cells revealed an increase in the percentage of proliferating cells within the MMTV/Crkll transgenic mice $(11.8 \%)$ relative to the wild-type mice (3.3\%) (Figure 3B). To determine whether the observed mammary epithelial abnormalities reflect the activation of known targets of Crk, we assessed Crk binding proteins and Crk associated pathways by Western blot analysis using whole cell lysates derived from mammary glands of 20-week-old mice. Several phosphorylated proteins were elevated in lysates derived from MMTV/Crkll transgenic mammary glands relative to FVB control littermates, which correlates with previous studies that observed enhanced tyrosine phosphorylation in whole cell lysates derived from v-crk transformed cells (See Supplemental Figure S3 at http://ajp.amjpathol.org). When the phosphorylation status of a known Crk binding partner, p130Cas, which is elevated in v-crk transformed cells, was examined, we observed variable phosphorylation levels in lysates from mammary glands demonstrating that known Crk binding partners are not significantly altered. Similarly, no significant changes in the activation of Akt and JNK kinases was observed in any of the seven MMTV/Crkll mice examined (data not shown), demonstrating that Crkll overexpression in vivo does not reflect pathways activated in $\mathrm{V}$-crk transformed fibroblasts grown in serum. However, a consistent elevation was observed in phospho-Erk1 and Erk2 when compared with matched controls (See Supplemental Figure S3 at $h$ ttp:// ajp.amjpathol.org). Our data implies that Crkll contributes to the enhanced branching morphogenesis observed in 20-week-old transgenic animals. Consistent with this, overexpression of the Crkll adaptor protein can contribute to branching morphogenesis in vitro. ${ }^{6}$

\section{Crkll Transgene Leads to the Formation of Atypical Mammary Architecture in Adult Nulliparous Mice}

In aging nulliparous transgenic mice at approximately 1 year of age, enhanced branching persists, with several small buds branching off the main ductal tree. Furthermore, several MMTV/CrkIl mice displayed atypical ductal structures, such as spiculated ends and lobuloalveoli, although they cannot be classified as hyperplastic (Fig-
Table 1. MMTV/CrkII tumor incidence

\begin{tabular}{lcl}
\hline \multicolumn{1}{c}{ Tumor pathology } & $\begin{array}{c}\text { Latency } \\
\text { (days) }\end{array}$ & Status \\
\hline Adenosquamous carcinoma & 327 & Multiparous \\
Fibroadenoma-like lesion & 466 & Nulliparous \\
Glandular carcinoma & 507 & Multiparous \\
Secretory glandular & 452 & Multiparous \\
$\quad$ carcinoma & & \\
Radial scar & 449 & Nulliparous \\
Unknown & 471 & Nulliparous \\
\hline
\end{tabular}

Mice from two MMTV/Crkll transgenic lines were divided into two groups-nulliparous or multiparous-and monitored for tumor development. MMTV/Crkll mice show a combined rate of tumor incidence of $17.6 \%$ (6/34), whereas age-matched FVB developed tumors with an incidence of $4 \%(1 / 25)$.

ure $3 \mathrm{C}$ ). Other stages of mammary gland development were also examined (See Supplemental Figure S4 at http://ajp.amjpathol.org). Transgenic mice examined at days 10 and 18 of pregnancy showed no alterations compared with control animals when assessed by wholemount analysis and histology. Furthermore, no significant changes in lactation or involution were observed in the MMTV/Crkll transgenic mice relative to control mice (See Supplemental Figure S4 at http://ajp.amjpathol.org). Hence, Crkll overexpression in the mammary epithelium disrupts early development, promotes enhanced branching and other atypical branching structures, but does not lead to obvious changes during pregnancy, lactation, and involution.

\section{Elevated Levels of Crkll Predispose the Mammary Epithelium to Tumorigenesis}

To determine whether overexpression of Crkll could lead to the development of mammary tumors, two cohorts of mice (nulliparous and multiparous) were established for the 6396 and 6398 transgenic lines. In the two lines studied, lobular hyperplasia was evident in the MMTV/ Crkll multiparous transgenic mice relative to the wild-type mice (data not shown). Tumor development was monitored in both nulliparous and multiparous females. This revealed a combined tumor incidence of $17.6 \%(6 / 34)$ and a tumor latency of approximately 445 days $(\sim 14.8$ months). By contrast, the tumor incidence in female FVB control mice was $4.0 \%(1 / 25)$ with a similar latency of 461 days ( $\sim 15.3$ months). The tumors from the MMTV/CrkII mice were of a diverse phenotype, including fibroadenoma-like lesions, glandular carcinoma, secretory glandular carcinoma, and squamous adenocarcinoma (Table 1, Figure 4). No metastatic lesions were found in any animals. The induction of mammary tumors in the MMTV/ Crkll mice was accompanied by an increase in the overall levels of Crk protein (Figure 4, Figure 5).

Crkll lesions were further characterized for markers characteristic of these tumor pathologies. Fibroadenomalike lesions consisted of several lineages of differentiated epithelial cells (as noted by staining for CK8, CK14, and SMA) interspersed within mesenchymal cell populations (vimentin, SMA) (Figure 5A). The squamous adenocarcinoma, characterized by a high mitotic index and the 


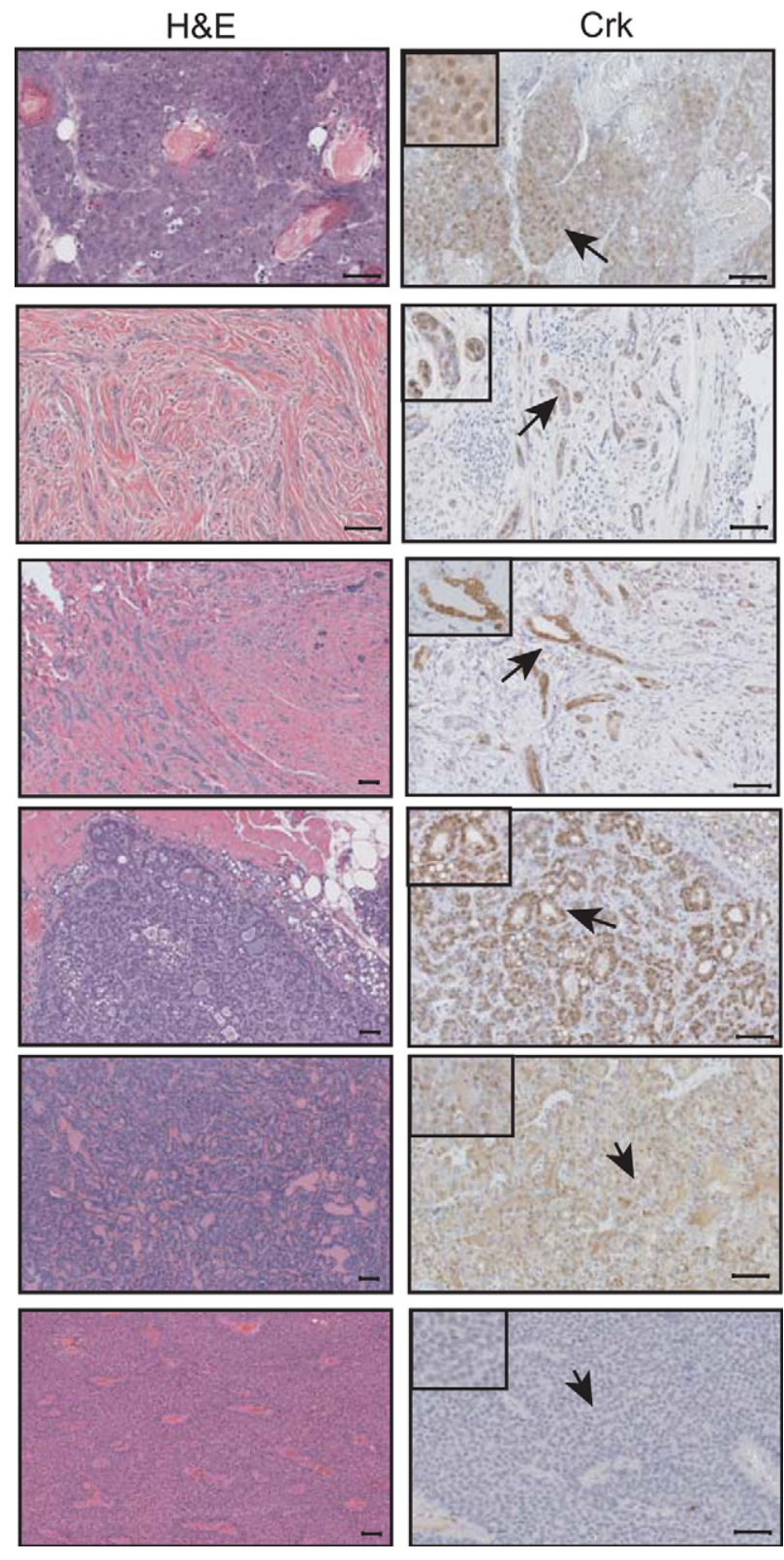

Figure 4. Overexpression of CrkII leads to tumor development. Analysis of H\&E-stained paraffin-embedded sections of MMTV/CrkII tumors reveals several different pathologies, such as adenosquamous carcinoma (top left panel), fibroadenoma-like lesions (second left panel), radial scars (third left panel), glandular carcinoma (fourth left panel), and secretory glandular carcinoma (fifth left panel). All tumors were Crk positive (first through fifth right panels), whereas the FVB carcinoma (lower left and right panels) was not positive for Crk. Images taken at $\times 20$, except the bottom four left panels, which were taken at $\times 10$. Scale bar $=50 \mu \mathrm{m}$. Arrows represent positive staining in the CrkII tumors and the lack of staining in the FVB tumor.

presence of cytokeratin pearls, stained positive for CK14 and SMA (myoepithelial markers), as well as CK6 (a putative progenitor cell marker) and CK8 (luminal epithelial marker), suggesting that this tumor was of a mixed cellular lineage (Figure 5B). Quantitative RT-PCR specific for the transgene confirmed that the tumor was indeed positive for the Crkll transgene (data not shown). Thus, overexpression of Crkll can lead to tumor development, albeit at a low incidence and with a long latency. The tumors that formed in MMTV/Crkll mice were of diverse
A

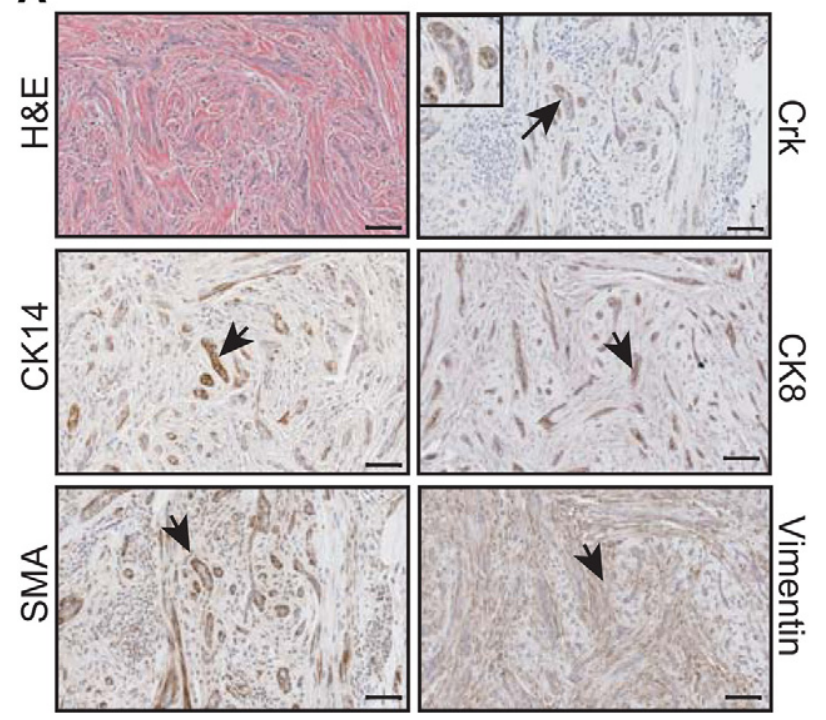

B
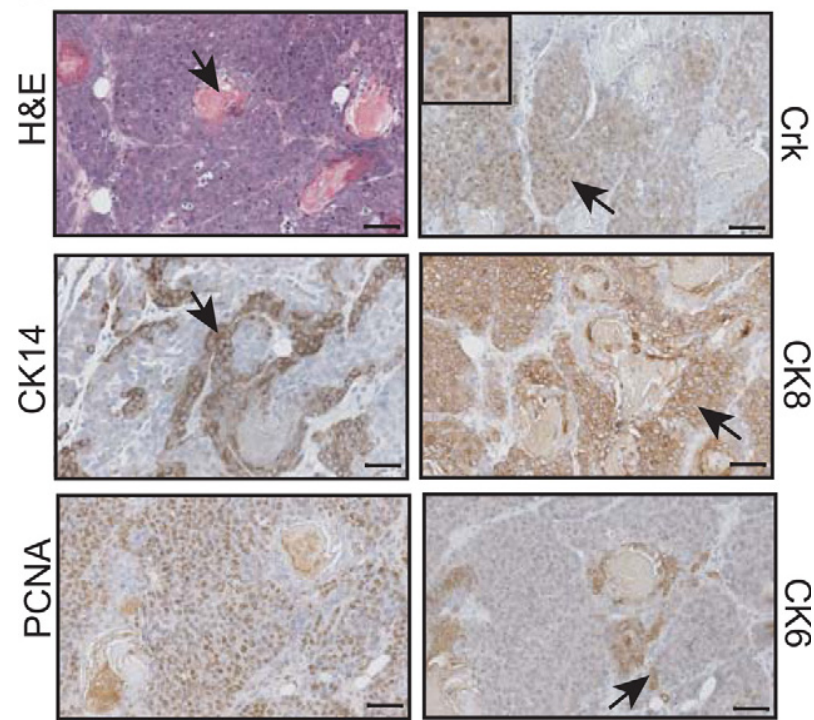

Figure 5. MMTV/CrkII overexpression leads to tumor development. A: A focal fibroadenoma-like lesion in an aging nulliparous mouse at 446 days of age (upper left panel) expressed Crk, CK14, CK8, SMA, and vimentin. All images taken at $\times 20$; scale bar $=50 \mu \mathrm{m}$. Arrows represent positive staining. B: An adenosquamous carcinoma (cytokeratin pearl illustrated by the black arrow, upper left panel) was found in a multiparous CrkII mouse at 397 days and expresses the Crk protein, CK14, CK8, and CK6 (see black arrows for positive staining within each respective panel). The tumor was highly proliferative, as illustrated by proliferating cell nuclear antigen staining.

phenotypes and expressed different cellular markers that are characteristic of these tumor pathologies. No differences were noted in the average life expectancy of the MMTV/CrkII transgenic mice versus the control FVB mice.

\section{Overexpression of Crkll Leads to Alterations in Gene Expression that Impact Mammary Tumorigenesis}

To understand how overexpression of Crkll may impact tumorigenesis, we performed microarray analysis comparing the breast cancer cell line T47D with T47D cells 


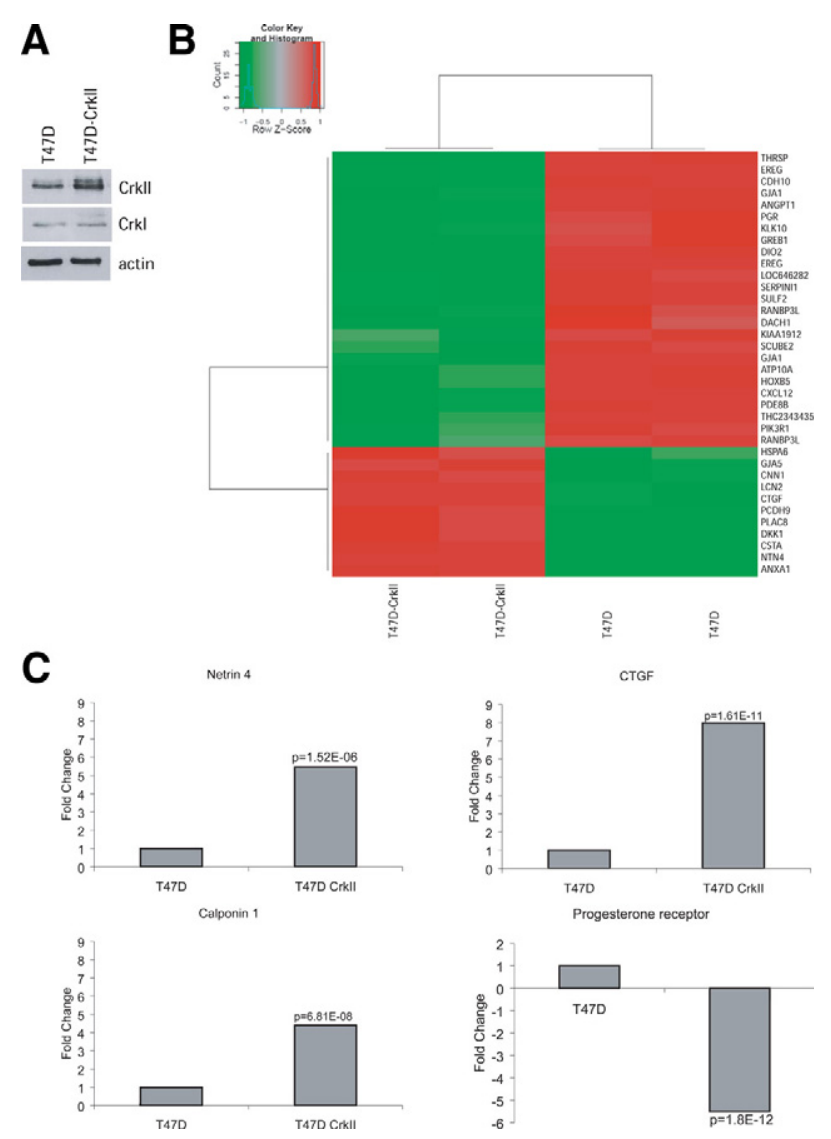

Figure 6. Overexpression of CrkII leads to alterations in gene expression in T47D cells. A: Expression of CrkII protein levels in T47D and T47D-CrkII cells. B: A heatmap illustrating the top up-regulated and down-regulated genes between T47D and T47D-CrkII cells is shown, using technical replicates as an additional control. C: Four of the top differentially expressed genes were validated using RT-PCR analysis, including netrin 4 (NTN4), connective tissue growth factor (CTGF), progesterone receptor (PR), and Calponin 1 (CNN1). For each gene to be validated, data from three independent experiments were collected and expressed as the average fold change between the T47D control cells and the T47D-CrkII cells. A student's $t$-test was performed on the data collected from the three experiments to determine significance.

overexpressing Crkll (Figure 6A). We chose this cell line as it is a well-differentiated breast cancer cell line and we have previously characterized these cells in vitro. ${ }^{5}$ In that study, we observed that overexpression of Crkll promotes cellular dispersal, with the T47D-Crkll cells acquiring a more mesenchymal phenotype, characterized by the loss of adherens junctions and reorganization of the actin cytoskeleton. ${ }^{5}$ The top 36 of 1850 differentially expressed genes between T47D and T47D-Crkll cells were identified and visualized as a heat map (Figure 6B). Examination of overrepresented Kyoto Encyclopedia of Genes and Genomes (KEGG) and Gene Ontology (GO) categories in the set of differentially expressed genes revealed that a number of biological processes important for tumor biology were significantly altered in T47D-Crkll cells, including cellular adhesion, migration, cytoskeletal organization, regulation of Rho GTPases, proliferation, and regulation of the cell cycle (See Supplemental Figures S5 and S6, along with Supplemental Tables 1-3 at http://ajp.amjpathol.org). These results imply that deregulation of Crkll could give rise to changes in gene expres- sion required, but not sufficient, for tumorigenesis. Interestingly, of the many genes altered in the Crkll overexpressing cells, several also have functions implicated in mammary gland development, including Netrin 4, Calponin 1, CTGF, and the progesterone receptor. Each of these genes were validated through quantitative real-time PCR (Figure 6C).

\section{CTGF and Netrin-4 Are Elevated in the Mammary Glands of MMTV/Crkll Transgenic Mice}

To examine whether any of the gene targets from the T47D-Crkll cells could correlate with the observed mammary epithelial biology observed in the MMTV/Crkll transgenic mice, we performed Western blot analysis to assess the protein levels of two differentially expressed gene targets (CTGF and netrin-4). CTGF is involved in regulating lactogenic differentiation of mouse mammary epithelial cells and is highly expressed during pregnancy and lactation, ${ }^{22}$ whereas netrin-4 has no known role in the mammary gland, although it has been shown to mediate branching morphogenesis of lungs and salivary glands. ${ }^{23,24}$ Whole cell lysates derived from mammary glands, revealed that both CTGF and netrin-4 were elevated in lysates derived from MMTV/Crkll transgenic mammary glands relative to FVB control littermates, thus, correlating with the gene profiling data (Figure 7A). Densitometry of Western blots revealed a significant elevation in the expression of both CTGF and netrin-4 in MMTV/ Crkll transgenic mice relative to the wild-type littermates (Figure 7B). It is interesting that immunohistochemistry of netrin-4 revealed strong staining surrounding the terminal end bud structures in the MMTV/Crkll transgenic mice, which correlated with the expression of laminin, an extracellular matrix component that has been shown to associate with netrin-4 (Figure 7C). As the co-localization of netrin-4 and laminin has been associated with impaired branching morphogenesis of the salivary gland, ${ }^{23}$ these data imply that netrin-4 may play a role in delayed ductal outgrowth in the MMTV/Crkll mice.

\section{Elevated Levels of Collagen Isoforms in Crkll Transgenic Mammary Epithelium Are Associated with Delayed Ductal Outgrowth}

To further investigate how overexpression of Crkll may alter mammary gland development, we examined the subset of differentially expressed genes associated with the extracellular matrix (Figure 8A). Interestingly, this revealed that several collagen isoforms were elevated when Crkll was overexpressed in T47D cells, one of which, collagen type12 alpha1, was validated by RT-PCR (Figure 8, A and B). The elevation of collagen isoforms in T47D-Crkll cells correlates with histological sections of MMTV/CrkII mammary glands, which revealed disorganized and thickened collagenous stroma surrounding the terminal end buds when compared with normal FVB littermates (Figure 8C). This phenotype was characterized by increased collagen surrounding the terminal end 
A

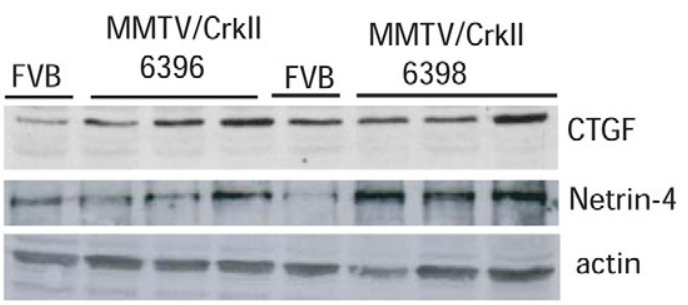

B
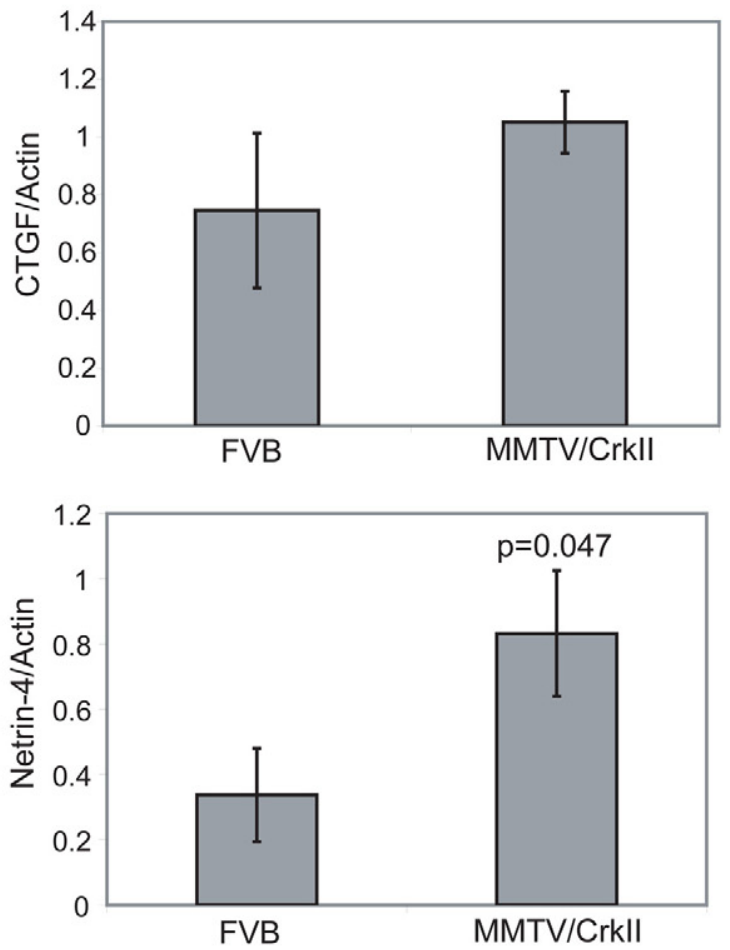

C

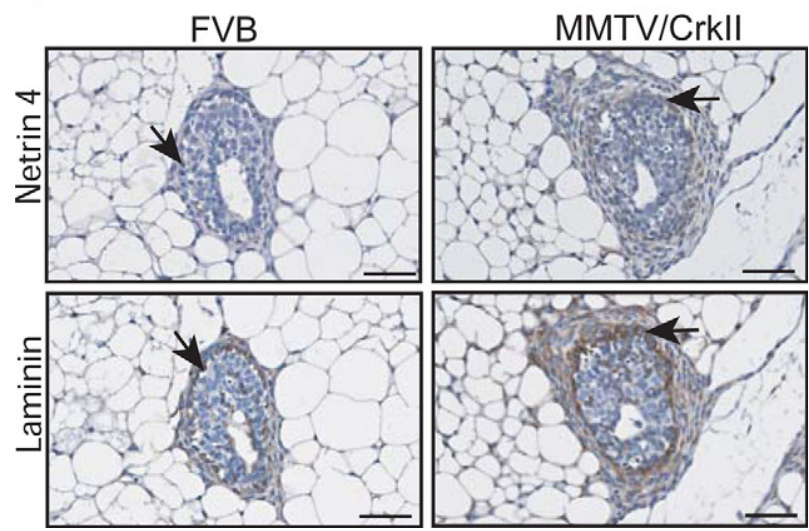

Figure 7. Enhanced CTGF and Netrin-4 protein levels are found in mammary tissue derived from MMTV/CrkII transgenic mice. A: Western blot analysis illustrating enhanced CTGF and Netrin-4 levels in MMTV/CrkII transgenic mice relative to wild-type FVB mice at 20 weeks of age. B: Densitometry of CTGF and netrin- 4 in relation to actin levels. The ratio of CTGF to actin per mouse was calculated and the average ratios from the wild-type mice and the MMTV/CrkII transgenic mice were compared, \pm SE. Netrin- 4 levels were calculated in the same manner. C: Immunohistochemistry on paraffin sections from mice at 10 weeks of age reveals positive netrin- 4 staining surrounding the terminal end buds of transgenic mice (see black arrows) with very little positive netrin-4 staining in FVB littermates. Laminin is present in both wild-type and MMTV/CrkII transgenic mice (see black arrows). All images taken at $\times 20$. Scale bar $=50 \mu \mathrm{m}$. buds, as determined by Trichrome staining, and indicates a mechanism through which Crkll overexpression may result in delayed development of the mammary gland during puberty (Figure $8 \mathrm{C}$ ). Crk protein was observed in the terminal end buds surrounded by collagen, but was relatively absent in all FVB littermates tested ( $n=$ 5) (Figure 8C).

Interestingly, when mammary wholemounts were imaged and quantified for stromal content (ie, fibroblasts, extracellular matrix, immune cells), only $20 \%$ of terminal end buds examined in FVB mice had stroma encompassing the leading edge of the terminal end bud, as observed as a "halo-like" structure surrounding the terminal end buds (see Supplemental Figure S7 at http://ajp.amjpathol.org) and Materials and Methods. In contrast, $62 \%$ of the MMTV/CrkII terminal end buds were encased in these "halo-like" structures, suggesting enhanced stromal content (Figure 8D). These observations correlate with the histological images of enhanced collagen surrounding MMTV/Crkll terminal end buds, although other stromal cellular components may be present. For instance, in mammary gland development, macrophages are required for proper ductal elongation, as well as remodeling of the extracellular matrix. ${ }^{25}$ Since macrophages can influence both fibroblast proliferation and collagen deposition, ${ }^{25} \mathrm{~F} 4 / 80$ staining was performed to assess for any potential differences in macrophage recruitment to the terminal end buds of MMTV/Crkll and wild-type mice. No significant difference in the number of $\mathrm{F} 4 / 80$ positive macrophages was observed between MMTV/Crkll mammary glands and wild-type mice (Figure 8, E and F). Thus, the Crkll associated collagen deposition surrounding the terminal end buds correlates with delayed ductal outgrowth within MMTV/Crkll transgenic mice.

\section{Discussion}

This study provides direct evidence that elevated levels of Crkll in the mammary epithelium of transgenic mice interferes with normal mammary gland development and induces mammary epithelial tumors, albeit with low incidence. The Crkll transgene exhibited expression that is characteristic of the MMTV promoter, with higher levels of expression in the lactating gland as compared with the nulliparous state. ${ }^{19}$ Immunohistochemistry revealed mosaic staining for the transgene throughout the mammary luminal epithelium and within ducts. This most likely reflects the nature of the MMTV promoter, as several other MMTV mouse models also show heterogeneous staining. ${ }^{19,26}$ Crkll was localized in both the nucleus and cytoplasm of the mammary epithelial cells. Although most studies have focused on the role of Crk proteins as adaptor proteins in the cytoplasm, others have identified Crkll in the nucleus. For instance, Miller and colleagues ${ }^{7}$ found Crkll in the nucleus and cytoplasm in lung adenocarcinomas. Several Crkll SH3N binding partners, such as DOCK180 and Abl were also found to be associated with Crkll in the nucleus. ${ }^{27}$ Although that study identified Crkll as a mediator of apoptosis when targeted to the nucleus, Crkll may play additional nuclear roles. Terminal deoxy- 


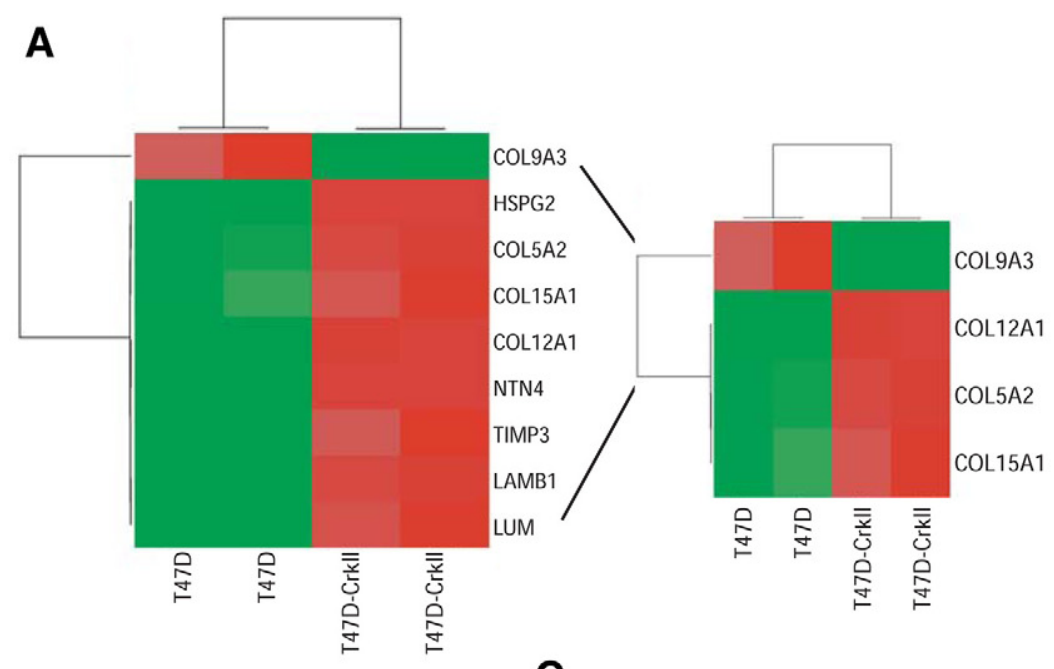

B

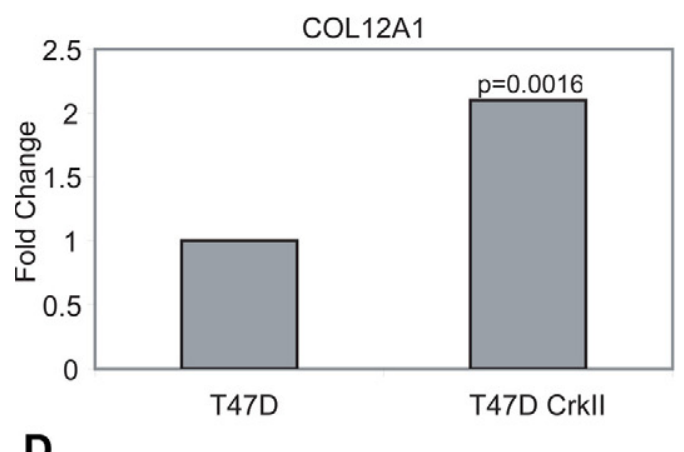

D

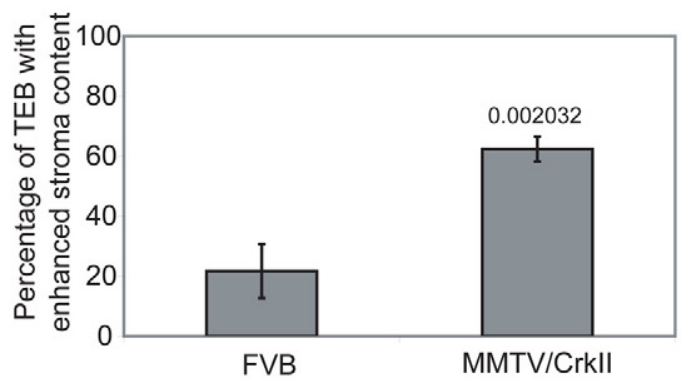

E

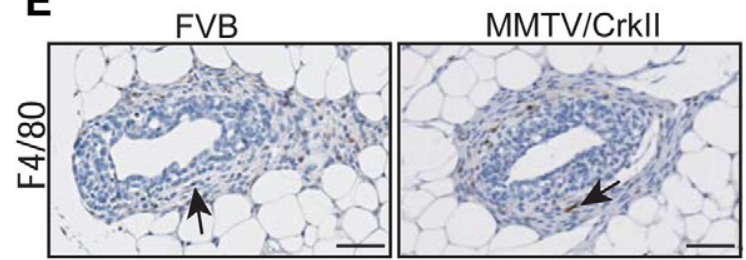

C
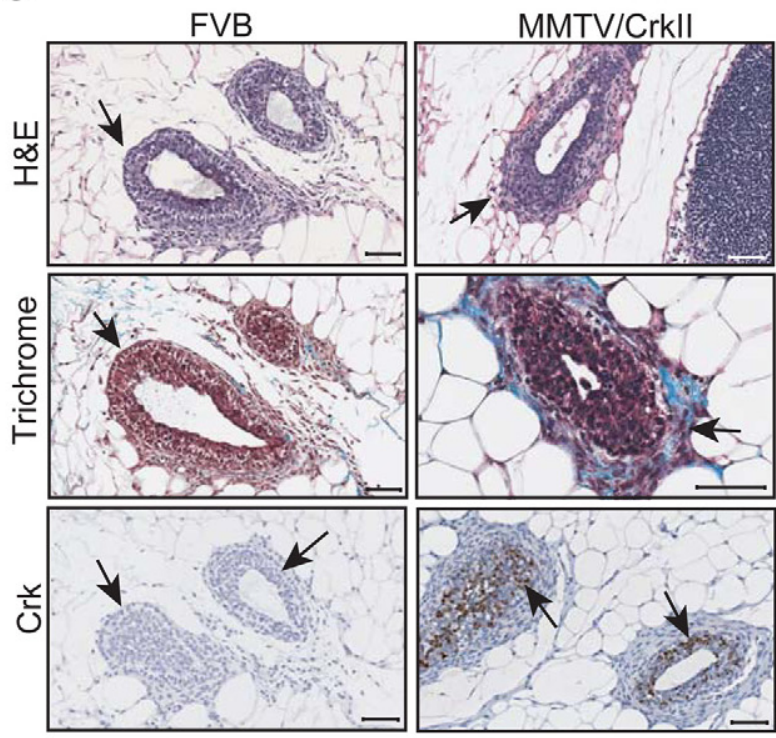

$F$

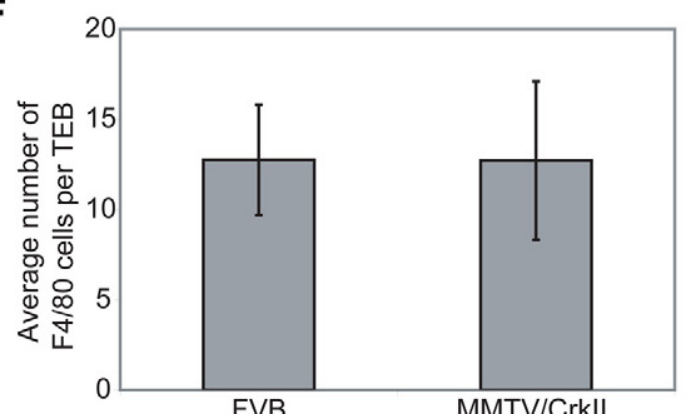

Figure 8. Overexpression of CrkII results in enhanced collagen deposition, which is associated with delayed ductal outgrowth during puberty. A: Heat map of differentially expressed genes associated with the extracellular matrix, using technical replicates as an additional control. The subset of differentially expressed collagen genes from the extracellular matrix heat map are represented in a collagen signature. B: Collagen type12 alpha1 differential expression was validated using RT-PCR analysis. Data from three independent experiments were collected and expressed as the average fold-change between the T47D control cells and the T47D-CrkII cells. A student's $t$-test was performed on the data collected from the three experiments to determine significance. C: Comparison of FVB terminal end buds (left panels) to those from MMTV/CrkII transgenic mice (right panels) shows that CrkII terminal end buds have increased collagenous stroma (see black arrow, upper right panel) encompassing the end bud. Trichrome staining revealed that increased collagen surrounds the MMTV/CrkII terminal end buds but not FVB terminal end buds (see black arrows). Immunohistochemistry reveals that Crk is indeed expressed in the terminal end buds of transgenic mice (see black arrow) but not in FVB littermates. All images taken at $\times 20$. Scale bar $=50 \mu \mathrm{m}$. D: The percentage of terminal end bud structures encompassed by stroma ("halo-like structures") in FVB versus MMTV/CrkII mice $\pm \mathrm{SE}, P<0.05$. E: Immunohistochemistry identifies F4/80 positive macrophages (see black arrows) surrounding the terminal end buds of both MMTV/CrkII and FVB mice. All images taken at $\times 20$. Scale bar $=50 \mu \mathrm{m}$. F: F4/80 macrophages were scored in a blinded fashion and averaged over the total number of terminal end buds counted, \pm SE. The average number of F $4 / 80$ macrophages was not significantly different between the wild-type and MMTV/CrkII transgenic mice. 
nucleotidyl transferase dUTP nick-end labeling staining in the nulliparous mammary glands did not reveal significant apoptosis, thus, the role of Crkll in the nucleus could depend on context, tissue and other proteins. Furthermore, CrkL plays an active role in the nucleus, functioning to regulate transcription within many different cell types, however, few studies have examined the role of Crkll in this context. $28-31$

Mammary gland development initiates during embryogenesis; however, the majority of mammary gland development occurs during the onset of puberty. Beginning at 3 weeks of age, terminal end buds form and begin the process of ductal elongation until they have reached the edge of the fat pad, whereupon they regress. ${ }^{20}$ MMTV/ Crkll mice exhibited a developmental abnormality such that ductal outgrowth was delayed at 5 weeks of age and was not complete at 12 weeks of age, when the mammary fat pad is normally filled with epithelial ducts (Figure 2). Although higher MMTV/Crkll expression in virgin animals was not evident through Western blot analysis (which contains not only epithelia but also stroma and adipocytes), immunohistochemistry on paraffin embedded sections showed positive Crk staining in the terminal end bud epithelia of the virgin mammary glands of the MMTV/Crkll animals, but not in those of the FVB control mice.

This suggests that the overexpression of Crkll within the terminal end bud structures is responsible for the delay in ductal outgrowth. Indeed, other studies have demonstrated that the MMTV promoter is active in the terminal end buds. ${ }^{19}$ This retarded phenotype is similar to other mouse models, such as MMTV/heregulin, MMTV/ EphB4, MMTV/Cripto, and mice overexpressing either Krct or p190-B Rho GTPase. ${ }^{26,32-35}$ For MMTV/Crkll mice, delayed outgrowth is associated with increased collagen surrounding the terminal end buds, with no significant changes in cellular proliferation, apoptosis, cell-cell contact, differentiation, or macrophage recruitment despite the increased diameter of the terminal end buds themselves (Supplemental Figure S1 and S2 at http://ajp.amjpathol.org).

Gene expression profiling revealed that overexpression of Crkll results in enhanced expression of netrin-4, a secreted protein that is structurally related to laminin $\beta$ chains and is expressed in various tissues, including the kidney, ovary, lung, and heart. ${ }^{23,24}$ Although netrin-4 has not previously been observed in mammary tissues, netrin- 1 and several netrin receptors have been identified in mammary epithelium. ${ }^{36,37}$ Netrin-4 is secreted by epithelial cells and is often deposited into the basement membrane. ${ }^{23}$ Several studies have identified netrin-4 as being an antagonist during branching morphogenesis of the lung and kidney, and that its inhibitory effects were associated with laminin co-localization. ${ }^{23,24}$ Whether netrin-4 alters laminin signaling to epithelial cells or whether integration of netrin-4 into the laminin network enhances its presentation to a putative receptor has yet to be determined. ${ }^{23}$ Our study has revealed positive netrin-4 staining surrounding the terminal end buds of MMTV/ Crkll transgenic mice, which correlates with strong laminin staining. These data support the hypothesis that en- hanced production of netrin-4 contributes to delayed ductal outgrowth in the MMTV/Crkll transgenic mice.

Additional analysis of gene expression changes associated with T47D-Crkll cells implies that overexpression of Crkll results in enhanced production of several collagen isoforms, which may alter the finely tuned stromal-epithelial interaction. Interactions between the stroma and epithelium occurs during ductal outgrowth, when the invading epithelium must communicate with the stroma to co-ordinate the invasion of the terminal end buds; however, the mechanism by which this cross talk regulates branching morphogenesis in vivo is not well understood. Alterations to the adjacent stromal microenvironment, such as enhanced collagen observed in MMTV/Crkll transgenic mice, could have profound effects on mammary outgrowth. Weaver and colleagues demonstrated that matrix rigidity plays a critical role in epithelial morphogenesis by altering cell-cell/cell-matrix adhesion as well as cell polarity.38 This can have profound effects on cellular proliferation and can compromise cellular architecture. We did not observe significant alterations in cellular proliferation or apoptosis within the terminal end bud structures of MMTV/Crkll transgenic mice. However, the $10 \%$ increase in $\mathrm{Ki}-67-$ positive cells in the MMTV/Crkll terminal end buds, coupled with their enlarged diameter, as compared with wild-type mice, suggests that there may be a subtle alteration in proliferation that was missed at the time points examined. In conclusion, Crkll is a critical regulator of mammary gland outgrowth, as even subtle changes in the levels of Crk expression can upset normal development.

Although overexpression of Crkll results in the delayed outgrowth of the mammary epithelia, the ductal tree eventually filled the fat pad at later time points (ie, 14 weeks). In post-pubertal mice, MMTV/Crkll transgenic glands displayed enhanced side branching, which is associated with increased proliferation (Figure 3). We confirmed that altered branching patterns in MMTV/Crkll mice were not due to changes in the estrous cycle (data not shown). Consistent with this, mice overexpressing p130Cas, a major binding partner of Crk, also display a similar phenotype. ${ }^{39}$ Furthermore, other adaptor proteins such as Shc and Grb2 show a comparable phenotype when driven by the MMTV promoter, suggesting that these adaptor proteins may potentiate the action of specific growth factors during normal mammary gland development. ${ }^{40}$ Interestingly, Crkll is downstream from several growth factors that have been shown to be required for branching morphogenesis, either in vitro or in vivo, such as epidermal growth factor, hepatocyte growth factor, and insulin-like growth factor. ${ }^{41-44}$ Although we were unable to observe significantly elevated phosphorylation levels of p130Cas, a major Crk binding partner, we observed a consistent elevation of phospho-Erk $1 / 2$ levels in MMTV/Crkll mice at 20 weeks of age, when compared with wild-type mice. Interestingly, in MMTV/p130Cas transgenic mice, enhanced branching is associated with increased MAPK signaling. ${ }^{39}$

Lobular hyperplasia was significant in the MMTV/Crkll multiparous transgenic mice relative to the wild-type mice (data not shown), although aging FVB mice can develop hyperplasia due to pituitary abnormalities. ${ }^{45,46}$ Overex- 
pression of Crkll may aid in the progression of these naturally occurring lesions. In support of this, Crkl/II are significantly overexpressed in poorly differentiated lung tumors, suggesting a potential role for Crk proteins in the progression from early to advanced states of disease. ${ }^{7}$

Although tumor incidence was low in MMTV/CrkII transgenic mice, tumor development was found in both nulliparous and multiparous females, with a combined tumor incidence of $17.6 \%$ and a tumor latency of 445 days (Table 1). The long latency and low incidence suggests that other genetic events are required for tumor onset. These results are important since overexpression of other adaptor and scaffold proteins, p130Cas, Grb2, and Gab2 were unable to induce tumor formation. ${ }^{39,40,47}$ Consistent with the Crkll data, mice overexpressing Shc also have a low tumor incidence of $7 \% .{ }^{40}$ The low tumor incidence of Crkll transgenic mice may be associated with its linker region, containing the Y221 negative regulatory site and its $\mathrm{SH} 3$ domain at the $\mathrm{C}$-terminus. ${ }^{48}$ Phosphorylation of Y221 by binding partners such as Abl results in the auto-inhibitory structure of Crkll, thus preventing binding by any $\mathrm{SH} 3$ binding partners. ${ }^{49,50}$

Interestingly, the lesions found in MMTV/CrkII nulliparous mice were benign, as compared with tumors found in MMTV/Crkll multiparous animals, suggesting that elevated transgene expression may play a role in malignancy (Table 1). Within the tumors identified in the multiparous cohorts, one Crkll tumor was identified as a squamous adenocarcinoma, with a high mitotic index and the presence of cytokeratin pearls. Quantitative RTPCR specific for the transgene confirmed that this tumor is indeed positive for the Crk transgene. The pathology of the Crkll tumor is similar to MMTV models in which the Wnt pathway is active. ${ }^{51}$ These features are reminiscent of those seen in human basal breast cancers, which are correlated with poor prognosis. ${ }^{52}$ Basal-like tumors are a distinct subset of breast cancer that expresses genes characteristic of basal epithelial cells, including progenitor cells (CK6), and myoepithelial cells (CK14). ${ }^{53}$ Indeed, staining in the Crkll adenosquamous carcinoma was positive for CK14 (myoepithelial marker), CK8 (epithelial marker), as well as CK6 (a putative progenitor marker), suggesting that this tumor may be of mixed cellular lineage (Figure 5). Consistent with the MMTV-Wnt mice, there were two predominant cellular components-luminal (CK8+) and myoepithelial $(\mathrm{CK} 14+),{ }^{51}$ suggesting that transformation occurs from a bipotential cell.

Genes differentially expressed were evaluated with Kyoto Encyclopedia of Genes and Genomes (KEGG) and Gene Ontology (GO) pathway analysis programs, in which genes have been categorized based on their molecular function and biological processes. A recent microarray-based study by Kouros-Mehr and Werb ${ }^{54}$ identified genes and pathways thought to be involved in regulating branching morphogenesis of the mammary gland, and interestingly, we found several of these biological processes significantly altered in the T47D-CrkII expression profile, such as cell cycle, actin cytoskeleton reorganization, and cellular adhesion. In addition, several genes involved in the regulation of Rho GTPases were detected in the Crkll overexpressing cells (See Supple- mental Figures S5 and S6 at http://ajp.amjpathol.org). ${ }^{54}$ This microarray data correlates with the phenotypes observed in MMTV/Crkll mice, as recent studies have identified Rho GTPases as critical regulators of mammary epithelial branching morphogenesis. ${ }^{32,55}$

In conclusion, we demonstrate that overexpression of Crkll is associated with altered mammary gland development and accelerated tumor development. Based on the results obtained from the MMTV/Crkll transgenic mice and the microarray profile obtained from the T47D-Crkll cells, overexpression of Crkll alters mammary gland development in a multifactorial manner. Although the low incidence of tumors in our transgenic mouse model highlights the fact that Crkll is not a strong oncogene, the ability of Crkll to induce a branching phenotype during a normally quiescent state suggests that it plays an active role in proliferation and epithelial remodeling. This precocious development, combined with the fact that Crkll is downstream of several signaling proteins involved in breast cancer development, highlights the potential consequence of increased Crk proteins in the human disease.

\section{Acknowledgments}

We thank Anie Monast for her technical assistance with the mouse colonies. In addition, we thank Hong Zhao, Naila Chughtai, and Sean Cory for their assistance with the microarray hybridization and analysis. We thank members of the Park and Cardiff laboratories for helpful comments and support. We thank Robert Annan for critically reviewing the manuscript.

\section{References}

1. Mayer BJ, Hamaguchi M, Hanafusa $\mathrm{H}$ : A novel viral oncogene with structural similarity to phospholipase C. Nature 1988, 332:272-275

2. Feller SM: Crk family adaptors-signalling complex formation and biological roles. Oncogene 2001, 20:6348-6371

3. ten Hoeve J, Morris C, Heisterkamp N, Groffen J: Isolation and chromosomal localization of CRKL, a human crk-like gene. Oncogene 1993, 8:2469-2474

4. Reichman CT, Mayer BJ, Keshav S, Hanafusa H: The product of the cellular crk gene consists primarily of $\mathrm{SH} 2$ and $\mathrm{SH} 3$ regions. Cell Growth Differ 1992, 3:451-460

5. Lamorte L, Royal I, Naujokas M, Park M: Crk adapter proteins promote an epithelial-mesenchymal-like transition and are required for HGF-mediated cell spreading and breakdown of epithelial adherens junctions. Mol Biol Cell 2002, 13:1449-1461

6. Lamorte L, Rodrigues S, Naujokas M, Park M: Crk synergizes with epidermal growth factor for epithelial invasion and morphogenesis and is required for the met morphogenic program. J Biol Chem 2002, 277:37904-37911

7. Miller CT, Chen G, Gharib TG, Wang H, Thomas DG, Misek DE, Giordano TJ, Yee J, Orringer MB, Hanash SM, Beer DG: Increased C-CRK proto-oncogene expression is associated with an aggressive phenotype in lung adenocarcinomas. Oncogene 2003, 22:7950-7957

8. Rodrigues SP, Fathers KE, Chan G, Zuo D, Halwani F, Meterissian S, Park M: Crkl and Crkll function as key signaling integrators for migration and invasion of cancer cells. Mol Cancer Res 2005, 3:183-194

9. Nishihara H, Tanaka S, Tsuda M, Oikawa S, Maeda M, Shimizu M, Shinomiya H, Tanigami A, Sawa H, Nagashima K: Molecular and immunohistochemical analysis of signaling adaptor protein Crk in human cancers. Cancer Lett 2002, 180:55-61

10. Takino T, Nakada M, Miyamori H, Yamashita J, Yamada KM, Sato H: 
Crkl adapter protein modulates cell migration and invasion in glioblastoma. Cancer Res 2003, 63:2335-2337

11. Matsuda M, Tanaka S, Nagata S, Kojima A, Kurata T, Shibuya M: Two species of human CRK cDNA encode proteins with distinct biological activities. Mol Cell Biol 1992, 12:3482-3489

12. Iwahara $\mathrm{T}$, Akagi $\mathrm{T}$, Shishido $\mathrm{T}$, Hanafusa $\mathrm{H}$ : Crkll induces serum response factor activation and cellular transformation through its function in Rho activation. Oncogene 2003, 22:5946-5957

13. Senechal K, Halpern J, Sawyers CL: The CRKL adaptor protein transforms fibroblasts and functions in transformation by the BCRABL oncogene. J Biol Chem 1996, 271:23255-23261

14. Hemmeryckx B, van Wijk A, Reichert A, Kaartinen V, de Jong R, Pattengale PK, Gonzalez-Gomez I, Groffen J, Heisterkamp N: CrkI enhances leukemogenesis in BCR/ABL P190 transgenic mice. Cancer Res 2001, 61:1398-1405

15. White DE, Kurpios NA, Zuo D, Hassell JA, Blaess S, Mueller U, Muller WJ: Targeted disruption of beta1-integrin in a transgenic mouse model of human breast cancer reveals an essential role in mammary tumor induction. Cancer Cell 2004, 6:159-170

16. Lahlou H, Sanguin-Gendreau V, Zuo D, Cardiff RD, McLean GW, Frame MC, Muller WJ: Mammary epithelial-specific disruption of the focal adhesion kinase blocks mammary tumor progression. Proc Natl Acad Sci USA 2007, 104:20302-20307

17. Finak G, Bertos N, Pepin F, Sadekova S, Souleimanova M, Zhao H, Chen H, Omeroglu G, Meterissian S, Omeroglu A, Hallett M, Park M: Stromal gene expression predicts clinical outcome in breast cancer. Nat Med 2008, 14:518-527

18. Finak G, Sadekova S, Pepin F, Hallett M, Meterissian S, Halwani F, Khetani K, Souleimanova M, Zabolotny B, Omeroglu A, Park M: Gene expression signatures of morphologically normal breast tissue identify basal-like tumors. Breast Cancer Res 2006, 8:R58

19. Wagner KU, McAllister K, Ward T, Davis B, Wiseman R, Hennighausen L: Spatial and temporal expression of the Cre gene under the control of the MMTV-LTR in different lines of transgenic mice. Transgenic Res 2001, 10:545-553

20. Richert MM, Schwertfeger KL, Ryder JW, Anderson SM: An atlas of mouse mammary gland development. J Mammary Gland Biol Neoplasia 2000, 5:227-241

21. Hinck L, Silberstein GB: Key stages in mammary gland development: the mammary end bud as a motile organ. Breast Cancer Res 2005, 7:245-251

22. Wang W, Morrison B, Galbaugh T, Jose CC, Kenney N, Cutler ML: Glucocorticoid induced expression of connective tissue growth factor contributes to lactogenic differentiation of mouse mammary epithelial cells. J Cell Physiol 2008, 214:38-46

23. Schneiders Fl, Maertens B, Bose K, Li Y, Brunken WJ, Paulsson M, Smyth N, Koch M: Binding of netrin-4 to laminin short arms regulates basement membrane assembly. J Biol Chem 2007, 282:23750-23758

24. Liu Y, Stein E, Oliver T, Li Y, Brunken WJ, Koch M, Tessier-Lavigne M, Hogan BL: Novel role for Netrins in regulating epithelial behavior during lung branching morphogenesis. Curr Biol 2004, 14:897-905

25. Schwertfeger KL, Rosen JM, Cohen DA: Mammary gland macrophages: pleiotropic functions in mammary development. J Mammary Gland Biol Neoplasia 2006, 11:229-238

26. Nikolova Z, Djonov V, Zuercher G, Andres AC, Ziemiecki A: Cell-type specific and estrogen dependent expression of the receptor tyrosine kinase EphB4 and its ligand ephrin-B2 during mammary gland morphogenesis. J Cell Sci 1998, 111 (Pt 18):2741-2751

27. Kar B, Reichman CT, Singh S, O'Connor JP, Birge RB: Proapoptotic function of the nuclear Crk II adaptor protein. Biochemistry 2007, 46:10828-10840

28. Fish EN, Uddin S, Korkmaz M, Majchrzak B, Druker BJ, Platanias LC: Activation of a CrkL-stat5 signaling complex by type I interferons. J Biol Chem 1999, 274:571-573

29. Nautiyal J, Kumar PG, Laloraya M: 17Beta-estradiol induces nuclear translocation of $\mathrm{CrkL}$ at the window of embryo implantation. Biochem Biophys Res Commun 2004, 318:103-112

30. Ozaki K, Oda A, Wakao H, Rhodes J, Druker BJ, Ishida A, Wakui M, Okamoto S, Morita K, Handa M, Komatsu N, Ohashi H, Miyajima A, Ikeda Y: Thrombopoietin induces association of Crkl with STAT5 but not STAT3 in human platelets. Blood 1998, 92:4652-4662

31. Rhodes J, York RD, Tara D, Tajinda K, Druker BJ: CrkL functions as a nuclear adaptor and transcriptional activator in Bcr-Abl-expressing cells. Exp Hematol 2000, 28:305-310
32. Vargo-Gogola T, Heckman BM, Gunther EJ, Chodosh LA, Rosen JM: P190-B Rho GTPase-activating protein overexpression disrupts ductal morphogenesis and induces hyperplastic lesions in the developing mammary gland. Mol Endocrinol 2006, 20: $1391-1405$

33. Wechselberger $C$, Strizzi L, Kenney N, Hirota M, Sun $Y$, Ebert $A$, Orozco O, Bianco C, Khan NI, Wallace-Jones B, Normanno N, Adkins $\mathrm{H}$, Sanicola M, Salomon DS: Human Cripto-1 overexpression in the mouse mammary gland results in the development of hyperplasia and adenocarcinoma. Oncogene 2005, 24:4094-4105

34. Stairs DB, Notarfrancesco KL, Chodosh LA: The serine/threonine kinase. Krct, affects endbud morphogenesis during murine mammary gland development. Transgenic Res 2005, 14:919-940

35. Weinstein EJ, Leder P: The extracellular region of heregulin is sufficient to promote mammary gland proliferation and tumorigenesis but not apoptosis. Cancer Res 2000, 60:3856-3861

36. Srinivasan K, Strickland P, Valdes A, Shin GC, Hinck L: Netrin-1/ neogenin interaction stabilizes multipotent progenitor cap cells during mammary gland morphogenesis. Dev Cell 2003, 4:371-382

37. Strizzi L, Mancino M, Bianco C, Raafat A, Gonzales M, Booth BW Watanabe K, Nagaoka T, Mack DL, Howard B, Callahan R, Smith GH, Salomon DS: Netrin-1 can affect morphogenesis and differentiation of the mouse mammary gland. J Cell Physiol 2008, 216:824-834

38. Paszek MJ, Zahir N, Johnson KR, Lakins JN, Rozenberg GI, Gefen A, Reinhart-King CA, Margulies SS, Dembo M, Boettiger D, Hammer DA, Weaver VM: Tensional homeostasis and the malignant phenotype. Cancer Cell 2005, 8:241-254

39. Cabodi S, Tinnirello A, Di Stefano P, Bisaro B, Ambrosino E, Castellano I, Sapino A, Arisio R, Cavallo F, Forni G, Glukhova M, Silengo L, Altruda F, Turco E, Tarone G, Defilippi P: p130Cas as a new regulator of mammary epithelial cell proliferation, survival, and HER2-neu oncogene-dependent breast tumorigenesis. Cancer Res 2006, 66:4672-4680

40. Rauh MJ, Blackmore V, Andrechek ER, Tortorice CG, Daly R, Lai VK, Pawson T, Cardiff RD, Siegel PM, Muller WJ: Accelerated mammary tumor development in mutant polyomavirus middle $T$ transgenic mice expressing elevated levels of either the Shc or Grb2 adapter protein. Mol Cell Biol 1999, 19:8169-8179

41. Niemann C, Brinkmann V, Spitzer E, Hartmann G, Sachs M, Naundorf $\mathrm{H}$, Birchmeier W: Reconstitution of mammary gland development in vitro: requirement of c-met and c-erbB2 signaling for branching and alveolar morphogenesis. J Cell Biol 1998, 143:533-545

42. Pepper MS, Soriano JV, Menoud PA, Sappino AP, Orci L, Montesano $R$ : Modulation of hepatocyte growth factor and c-met in the rat mammary gland during pregnancy, lactation, and involution. Exp Cell Res 1995, 219:204-210

43. Xie W, Paterson AJ, Chin E, Nabell LM, Kudlow JE: Targeted expression of a dominant negative epidermal growth factor receptor in the mammary gland of transgenic mice inhibits pubertal mammary duct development. Mol Endocrinol 1997, 11:1766-1781

44. Ruan W, Kleinberg DL: Insulin-like growth factor I is essential for terminal end bud formation and ductal morphogenesis during mammary development. Endocrinology 1999, 140:5075-5081

45. Wakefield LM, Thordarson G, Nieto Al, Shyamala G, Galvez JJ, Anver MR, Cardiff RD: Spontaneous pituitary abnormalities and mammary hyperplasia in $\mathrm{FVB} / \mathrm{NCr}$ mice: implications for mouse modeling. Comp Med 2003, 53:424-432

46. Nieto Al, Shyamala G, Galvez JJ, Thordarson G, Wakefield LM, Cardiff RD: Persistent mammary hyperplasia in FVB/N mice. Comp Med 2003, 53:433-438

47. Bentires-Alj M, Gil SG, Chan R, Wang ZC, Wang Y, Imanaka N, Harris LN, Richardson A, Neel BG, Gu H: A role for the scaffolding adapter GAB2 in breast cancer. Nat Med 2006, 12:114-121

48. Abassi YA, Vuori K: Tyrosine 221 in Crk regulates adhesion-dependent membrane localization of Crk and Rac and activation of Rac signaling. EMBO J 2002, 21:4571-4582

49. Klemke RL, Leng J, Molander R, Brooks PC, Vuori K, Cheresh DA: CAS/Crk coupling serves as a "molecular switch" for induction of cell migration. J Cell Biol 1998, 140:961-972

50. Kobashigawa Y, Sakai M, Naito M, Yokochi M, Kumeta H, Makino Y, Ogura K, Tanaka S, Inagaki F: Structural basis for the transforming activity of human cancer-related signaling adaptor protein CRK. Nat Struct Mol Biol 2007, 14:503-510 
51. Li Y, Welm B, Podsypanina K, Huang S, Chamorro M, Zhang X, Rowlands T, Egeblad M, Cowin P, Werb Z, Tan LK, Rosen JM, Varmus HE: Evidence that transgenes encoding components of the Wnt signaling pathway preferentially induce mammary cancers from progenitor cells. Proc Natl Acad Sci USA 2003, 100: 15853-15858

52. Sorlie T, Perou CM, Tibshirani R, Aas T, Geisler S, Johnsen H, Hastie $T$, Eisen MB, van de Rijn M, Jeffrey SS, Thorsen T, Quist H, Matese JC, Brown PO, Botstein D, Eystein Lonning P, Borresen-Dale AL: Gene expression patterns of breast carcinomas distinguish tumor subclasses with clinical implications. Proc Natl Acad Sci USA 2001, 98:10869-10874

53. Fadare O, Tavassoli FA: Clinical and pathologic aspects of basal-like breast cancers. Nat Clin Pract Oncol 2008, 5:149-159

54. Kouros-Mehr H, Werb Z: Candidate regulators of mammary branching morphogenesis identified by genome-wide transcript analysis. Dev Dyn 2006, 235:3404-3412

55. Ewald AJ, Brenot A, Duong M, Chan BS, Werb Z: Collective epithelial migration and cell rearrangements drive mammary branching morphogenesis. Dev Cell 2008, 14:570-581 